Article

\title{
Disubstituted 4-Chloro-3-nitrophenylthiourea Derivatives: Antimicrobial and Cytotoxic Studies
}

\author{
Anna Bielenica ${ }^{1, *(\mathbb{D})}$, Giuseppina Sanna ${ }^{2}$, Silvia Madeddu ${ }^{2}$, Gabriele Giliberti ${ }^{2}$, \\ Joanna Stefańska ${ }^{3}$, Anna E. Kozioł ${ }^{4}$, Oleksandra Savchenko ${ }^{5}$, Paulina Strzyga-Łach ${ }^{1}$ (D), \\ Alicja Chrzanowska ${ }^{1}$, Grażyna Kubiak-Tomaszewska ${ }^{6}$ and Marta Struga ${ }^{1,7}$ \\ 1 Department of Biochemistry, Medical University, 02-097 Warszawa, Poland; \\ paulina.strzyga@gmail.com (P.S.-Ł.); chrzanow.a@gmail.com (A.C.); mstruga@wum.edu.pl (M.S.) \\ 2 Department of Biomedical Sciences, Section of Microbiology and Virology, University of Cagliary, \\ Cittadella Universitaria, 09042 Monserrato, Italy; g.sanna@unica.it (G.S.); silvia.madeddu@unica.it (S.M.); \\ ggiliberti@unica.it (G.G.) \\ 3 Department of Pharmaceutical Microbiology, Medical University, 02-007 Warszawa, Poland; \\ jstefanska@wum.edu.pl \\ 4 Faculty of Chemistry, Maria Curie-Sklodowska University, 20-031 Lublin, Poland; \\ anna.koziol@poczta.umcs.lublin.pl \\ 5 Ecotech Complex, Maria Curie-Sklodowska University, 20-031 Lublin, Poland; \\ oleksandra.savchenko@poczta.umcs.lublin.pl \\ 6 Department of Biochemistry and Pharmacogenomics, Faculty of Pharmacy, Medical University of Warsaw, \\ 02-097 Warszawa, Poland; grazynakubiak@poczta.onet.pl \\ 7 Laboratory of Centre for Preclinical Research, Medical University of Warsaw, 02-097 Warszawa, Poland \\ * Correspondence: abielenica@wum.edu.pl; Tel.: +48-22-572-06-93
}

Received: 5 September 2018; Accepted: 19 September 2018; Published: 21 September 2018

\begin{abstract}
Chloro-3-nitrophenylthioureas 1-30 were synthesized and tested for their antimicrobial and cytotoxic activities. Compounds exhibited high to moderate antistaphylococcal activity against both standard and clinical strains (MIC values 2-64 $\mathrm{g} / \mathrm{mL}$ ). Among them derivatives with electron-donating alkyl substituents at the phenyl ring were the most promising. Moreover, compounds 1-6 and 8-19 were cytotoxic against MT-4 cells and various other cell lines derived from human hematological tumors $\left(C_{50} \leq 10 \mu \mathrm{M}\right)$. The influence of derivatives 11, 13 and 25 on viability, mortality and the growth rate of immortalized human keratinocytes (HaCaT) was observed.
\end{abstract}

Keywords: antimicrobial activity; biofilm; cytotoxicity; thiourea derivatives; X-ray crystallography

\section{Introduction}

In the field of medical chemistry, thiourea derivatives are of great interest due to their synthetic utility and biological importance. The thiourea moiety is a structural part of many bioactive compounds, that display antimicrobial [1-5], antifungal [6], antitubercular [2,7,8], antiviral [9-12], and central nervous system stimulating [13-16] properties. Derivatives of this group are also viewed as one of the most promising classes of anticancer agents. 1,2,4-Triazole-linked (thio)urea conjugates have been described as cytotoxic and apoptosis inducing substances [17]. The same properties, supported by DNA topoisomerase II inhibition, were proved for podophylltoxin-thiourea congeners [18]. Diaryl thiourea derivatives bearing $1 \mathrm{H}$-indazole-3-amine scaffold displayed anti-angiogenic potential as selective multi-target receptor tyrosine kinase (RTK) inhibitors [19]. Particularly, they have blocked activities of VEGFR-2, Tie-2 and EphB4 kinases, thus as a result can prevent tumorigenesis. On the other hand, bis-thiazoles derived from disubstituted thioureas are supposed to be involved in the regulation of the expression of acetylcholinesterase (AChE) and butyrylcholinesterase (BuChE), overexpressed in 
pathological conditions; e.g., cancer [20]. Another group, thioureido benzenesulfonamide derivatives, was found to inhibit carbonic anhydrase CA IX, which triggers the migration of tumor cells and results in a raise of the aggressive/invasive phenotype of cancer [6]. Pyrimidinyl acyl thioureas have shown the ability to block Heat Shock Protein 90 (Hsp90) ATP binding site [21]. The role of this protein is stabilization and regulation of oncogenic client proteins, therefore designing its inhibitors is a novel cancer therapy method. What is more, in different types of cancer, overexpression and mutation of the epidermal growth factor receptor (EGFR) have been observed; thus, finding inhibitors of EGFR kinases among (thio)ureido-quinazoline derivatives is also a promising approach to tumor treatment [22,23]. It was proven that the anticancer potency of symmetrical 1,3-phenyl bis-thiourea compounds were combined with their tubulin-binding properties [24]. By halting mitosis of tumor cells in prometaphase, this lead to their death via apoptosis. A series of pyrimidine-thiourea conjugates were found to exhibit an inhibitory effect against histone lysine demethylase 1 (LSD1), overexpressed in gastric, prostate, lung, and breast cancer cells $[25,26]$. Moreover, miscellaneous thiourea derivatives carrying sulfonamide moieties were proven to possess antiproliferative properties by docking to the active site of the mitogen kinase enzyme (MK-2), controlling the signal transduction pathway in cell proliferation $[5,27,28]$. The cytotoxicity of acridinylthioureas originates from their ability to intercalate with DNA and as a result inhibit telomerase or topoisomerase action [29]. Thiourea-derived compounds were also employed in the field of coordination chemistry as versatile chelating agents. The $\mathrm{Ru}(\mathrm{II}), \mathrm{Pd}(\mathrm{II})$ and $\mathrm{Pt}(\mathrm{II})$-based complexes of $\mathrm{N}, \mathrm{N}$-disubstituted thioureas have exerted cytotoxic properties via DNA binding ability [30-32].

A noticeable cytotoxic potential of mentioned thiourea-derived compounds was observed against a wide range of solid tumors, such as breast $[4,6,17,21,23,32,33]$, lung $[4,20,22,23,27,29,31,34]$, liver [5], prostate [4,18,31-33], cervical [4,29,30], brain [20,24,29], gastric [25], or colon [27,29,35] carcinoma, as well as human leukemia [29]. Simultaneously some of them, when tested on normal human cells, were found to possess a low cytotoxicity profile $[1,17,20]$. The main structural element of anticancer active thioureas were the presence of "the butterfly-like" tricyclic ring of acridine [29] or other heterocycles, such as pyrimidine [5,6,21], quinoline [27], quinazoline [22,23], furane [32], benzimidazole [4], chrysene [33], benzodioxole [18], triazole [17] or thiazole [20]. On the other hand, the most promising functionalities of a terminal aromatic ring were mainly electron-withdrawing substituents, such as nitro [27,33,35], cyano [17], trifluoromethyl/methoxy [17,19], halogeno [5,20,22,23], but also electron-withdrawing-methoxy [18,21,25] and methyl [24] groups. Among them, compounds containing the nitro group attached to the aromatic moiety (e.g., nitrofurans, bisnaphthalimides) are typically used as antibiotics and antimicrobials [36,37]. The introduction of an additional deactivating substituent, such as a halogen atom, might increase the bioactivity of a disubtituted derivative, because of a stronger electronegativity effect achieved [1,2].

Prompted by the above facts and as a continuation of our interest in biologically active thioureas $[1,2,38]$, we report the synthesis of some new 4-chloro-3-nitrophenylthiourea derivatives and complete the cytotoxic profile of compounds of this group [2].

\section{Results and Discussion}

\subsection{Chemistry}

In this paper new 1,3-disubstituted thioureas 20-24 and 27-30 were synthesized from 4-chloro-3nitroaniline and variety of isothiocyanates (Scheme 1, Table 1). Reactions were conducted in anhydrous acetonitrile at room temperature. The structures of new compounds were established by spectroscopic methods ( $\left({ }^{1} \mathrm{H} N M R,{ }^{13} \mathrm{C}\right.$ NMR, MS, and IR). The derivatives 1-19 and 25-26 were obtained previously [2]. 
<smiles>Nc1ccc(Cl)c([N+](=O)[O-])c1</smiles><smiles>[R]NC(=S)Nc1ccc(Cl)c([N+](=O)[O-])c1</smiles>

Scheme 1. Synthesis of 4-chloro-3-nitrophenylthiourea derivatives 20-24, 27-30.

Table 1. Cytotoxicity and anti-HIV activity of 4-chloro-3-nitrophenylthiourea derivatives 1-30.

\begin{tabular}{|c|c|c|c|}
\hline Comp. & $\mathbf{R}$ & $\begin{array}{l}\mathrm{MT}-4{ }^{*} \\
{ }^{1} \mathrm{CC}_{50}[\mu \mathrm{M}]\end{array}$ & $\begin{array}{l}\text { HIV-1 } 1 \text { IIIB * } \\
{ }^{2} \mathrm{EC}_{50}[\mu \mathrm{M}]\end{array}$ \\
\hline 1 & 2-chlorophenyl & 8.8 & $>8.8$ \\
\hline 2 & 3-chlorophenyl & 7.0 & $>7.0$ \\
\hline 3 & 4-chlorophenyl & 7.0 & $>7.0$ \\
\hline 4 & 2-bromophenyl & 9.6 & $>9.7$ \\
\hline 5 & 3-bromophenyl & 8.0 & $>8.0$ \\
\hline 6 & 4-bromophenyl & 6.6 & $>6.6$ \\
\hline 7 & 2-fluorophenyl & 13.0 & $>13.0$ \\
\hline 8 & 3-fluorophenyl & 9.0 & $>9.0$ \\
\hline 9 & 4-fluorophenyl & 7.0 & $>7.0$ \\
\hline 10 & 3-chloro-4-fluorophenyl & 7.3 & $>7.3$ \\
\hline 11 & 3,4-dichlorophenyl & 7.9 & $>7.9$ \\
\hline 12 & 2,4-dichlorophenyl & 8.0 & $>8.0$ \\
\hline 13 & 3-chloro-4-methylphenyl & 8.0 & $>8.0$ \\
\hline 14 & 5-chloro-2-methylphenyl & 8.2 & $>8.2$ \\
\hline 15 & 3-(trifluoromethyl)phenyl & 8.0 & $>8.0$ \\
\hline 16 & 4-(trifluoromethyl)phenyl & 7.0 & $>7.0$ \\
\hline 17 & 4-iodophenyl & 7.8 & $>7.8$ \\
\hline 18 & 4-nitrophenyl & 7.0 & $>7.0$ \\
\hline 19 & 4-cyanophenyl & 8.2 & $>8.2$ \\
\hline 20 & 4-methylphenyl & 14.6 & $>14.6$ \\
\hline 21 & 4-methoxyphenyl & 35.0 & $>35.0$ \\
\hline 22 & 4-butyl-2-methylphenyl & 18.7 & $>18.7$ \\
\hline 23 & phenyl & 23.0 & $>23.0$ \\
\hline 24 & bicyclo[2.2.1]hept-2-yl & 16.0 & $>16.0$ \\
\hline 25 & benzyl & 36.7 & $>36.7$ \\
\hline 26 & 1-phenylethyl & 16.7 & $>16.7$ \\
\hline 27 & (2-methyl)prop-2-en-1-yl & 15.5 & $>15.5$ \\
\hline 28 & prop-2-en-1-yl & 43.0 & 43.0 \\
\hline 29 & 3-(methylsulfanyl)propyl & 33.7 & $>33.7$ \\
\hline 30 & furan-2-ylmethyl & 25.6 & $>25.6$ \\
\hline
\end{tabular}

${ }^{1}$ Compound concentration $(\mu \mathrm{M})$ required to reduce the viability of mock-infected MT- 4 cells by $50 \%$, as determined by the MTT method; ${ }^{2}$ Compound concentration $(\mu \mathrm{M})$ was required to achieve $50 \%$ protection of MT- 4 cells from the HIV-1 induced cytopathogenicy, as determined by the MTT method; * Reference compound—Efavirenz $\left(\mathrm{CC}_{50}=46 \mu \mathrm{M}, \mathrm{EC}_{50}=0.002 \mu \mathrm{M}\right)$.

\subsection{Antimicrobial Studies}

Newly obtained 4-chloro-3-nitrophenylthioureas 20-24 and 27-30 were evaluated for their in vitro antimicrobial activity against a set of bacterial and fungal strains. The initial testing by the disc diffusion method $[39,40]$ chose derivatives with meaningful antimicrobial properties. Considering the fact that all compounds exhibited activity against Gram-positive strains (GIZ $\geq 13 \mathrm{~mm}$ ), in the next step the minimal inhibitory concentrations (MIC) were assessed by the twofold serial microdilution method [41,42]. The results showed that all investigated compounds (except 21) exhibited the potential to moderate antibacterial potency, mainly against standard staphylococcal and M. luteus strains (Table 2). 
A close examination of the structures of the active compounds revealed that the nature of the substituent at the thiourea moiety governs their antimicrobial potential. In general, the most prominent activity against standard strains was confined to derivatives comprising the electron-donating alkyl groups at the $\mathrm{C} 2 / \mathrm{C} 4$ position of the aromatic ring $(\mathbf{2 0}, \mathbf{2 2})$. For these derivatives the MIC values ranged from 2 to $4 \mu \mathrm{g} / \mathrm{mL}$. The moderate activity (MIC range 8-16 $\mu \mathrm{g} / \mathrm{mL}$ ) towards staphylococci was denoted for bicyclo[2.2.1] hept-2-yl- (24), phenyl- (23), furan-2-ylmethyl- (30) and (thio)alkylthioureas (27, 29). What is more, compounds possessing an alkyl chain at the thiourea nitrogen (27-29) exerted some activity against $P$. vulgaris, representing Gram-negative strains (MIC 32-128 $\mu \mathrm{g} / \mathrm{mL}$ ). Only one analog of the series, 4-methoxyphenylthiourea (21), was devoid of activity against tested microorganisms.

The potency of thioureas $\mathbf{2 2}$ and $\mathbf{2 4}$ towards all hospital methicillin-resistant strains of S. epidermidis was $2-16$ stronger than the reference Ciprofloxacin (Table 3). The antistaphylococcal activity of other tested compounds was equal or 2-4 times higher than observed for the standard antibiotic. Selected strains (MRSE 405/11, 406/11, 409/11, 411/11, 422/11) were remarkably less susceptible for the presence of synthesized thiourea than for the reference drug. 
Table 2. Activity of compounds against standard bacterial strains, expressed as minimal inhibitory concentrations (MIC, $\mu \mathrm{g} / \mathrm{mL})$.

\begin{tabular}{|c|c|c|c|c|c|c|c|c|c|c|c|}
\hline Comp. & $\begin{array}{l}\text { S. aureus } \\
\text { NCTC } 4163\end{array}$ & $\begin{array}{c}\text { S. aureus } \\
\text { ATCC } 25923\end{array}$ & $\begin{array}{c}\text { S. aureus } \\
\text { ATCC } 6538\end{array}$ & $\begin{array}{c}\text { S. aureus } \\
\text { ATCC } 29213\end{array}$ & $\begin{array}{c}\text { S. epidermidis } \\
\text { ATCC } 35984\end{array}$ & $\begin{array}{l}\text { S. epidermidis } \\
\text { ATCC } 12228\end{array}$ & $\begin{array}{c}\text { B. subtilis } \\
\text { ATCC } 6633\end{array}$ & $\begin{array}{c}\text { B. cereus } \\
\text { ATCC } 11778\end{array}$ & $\begin{array}{l}\text { E. faecalis } \\
\text { ATCC } 29212\end{array}$ & $\begin{array}{c}\text { M. luteus } \\
\text { ATCC } 9341\end{array}$ & $\begin{array}{c}\text { M. luteus } \\
\text { ATCC } 10240\end{array}$ \\
\hline 20 & 2 & 2 & 4 & 2 & 4 & 4 & 4 & 4 & - & 4 & 4 \\
\hline 22 & 4 & 2 & 2 & 2 & 4 & 4 & 4 & 4 & - & 4 & 2 \\
\hline 23 & 16 & 16 & 16 & 16 & 16 & 16 & 8 & 8 & 16 & 4 & 8 \\
\hline 24 & 8 & 8 & 8 & 8 & 16 & 16 & 8 & 8 & - & 32 & 16 \\
\hline 27 & 16 & 16 & 16 & 16 & 16 & 16 & 16 & 8 & 64 & 16 & 32 \\
\hline 28 & 64 & 32 & 32 & 64 & 32 & 32 & 32 & 32 & 64 & 32 & 32 \\
\hline 29 & 16 & 16 & 16 & 16 & 16 & 16 & 16 & 8 & 64 & 16 & 32 \\
\hline 30 & 16 & 8 & 16 & 16 & 32 & 32 & 16 & 16 & 32 & 16 & 16 \\
\hline${ }^{*}$ Ref. & 0.25 & 0.5 & 0.25 & 0.5 & 0.25 & 0.25 & $<0.12$ & 0.25 & 1 & 1 & 2 \\
\hline
\end{tabular}

Table 3. Activity of compounds against hospital methicillin-resistant strains of Staphylococcus epidermidis (MRSE)—minimal inhibitory concentrations (MIC, $\mu$ g/mL).

\begin{tabular}{|c|c|c|c|c|c|c|c|c|c|c|}
\hline Comp. & $\begin{array}{l}\text { S. epidermidis } \\
\text { MRSE 403/11 }\end{array}$ & $\begin{array}{l}\text { S. epidermidis } \\
\text { MRSE 404/11 }\end{array}$ & $\begin{array}{l}\text { S. epidermidis } \\
\text { MRSE 405/11 }\end{array}$ & $\begin{array}{l}\text { S. epidermidis } \\
\text { MRSE 406/11 }\end{array}$ & $\begin{array}{l}\text { S. epidermidis } \\
\text { MRSE 407/11 }\end{array}$ & $\begin{array}{l}\text { S. epidermidis } \\
\text { MRSE 409/11 }\end{array}$ & $\begin{array}{l}\text { S. epidermidis } \\
\text { MRSE 411/11 }\end{array}$ & $\begin{array}{l}\text { S. epidermidis } \\
\text { MRSE 412/11 }\end{array}$ & $\begin{array}{l}\text { S. epidermidis } \\
\text { MRSE 413/11 }\end{array}$ & $\begin{array}{l}\text { S. epidermidis } \\
\text { MRSE 422/11 }\end{array}$ \\
\hline 20 & 16 & 16 & 16 & 16 & 16 & 16 & 16 & 32 & 16 & 32 \\
\hline 22 & 4 & 8 & 4 & 8 & 4 & 4 & 4 & 8 & 8 & 8 \\
\hline 23 & 16 & 16 & 16 & 16 & 16 & 16 & 16 & 32 & 16 & 16 \\
\hline 24 & 4 & 4 & 4 & 8 & 4 & 4 & 4 & 4 & 4 & 4 \\
\hline 27 & 32 & 32 & 32 & 32 & 32 & 32 & 32 & 64 & 32 & 64 \\
\hline 28 & 64 & 64 & 64 & 64 & 64 & 64 & 64 & 128 & 64 & 128 \\
\hline 29 & 32 & 32 & 32 & 32 & 32 & 32 & 32 & 32 & 32 & 32 \\
\hline 30 & 32 & 32 & 32 & 64 & 32 & 32 & 32 & 32 & 32 & 32 \\
\hline${ }^{*}$ Ref. & 16 & 64 & 4 & 0.5 & 64 & 2 & 4 & 64 & 32 & 4 \\
\hline
\end{tabular}


It is worth noting that the factor influencing the biological activity could be a molecular flexibility. It is evident from the determined crystal structures of $\mathbf{2 0}$ and $\mathbf{2 4}$ that molecules of this group of derivatives are able to adopt different conformations (Figure 1). Variable orientations of the thiourea $\mathrm{C}=\mathrm{S}$ bond versus either 4-chloro-3-nitrophenyl or the second substituent could be described as cis-trans and trans-cis, respectively. Further, the patterns of intermolecular hydrogen bonding are specific for given conformers.

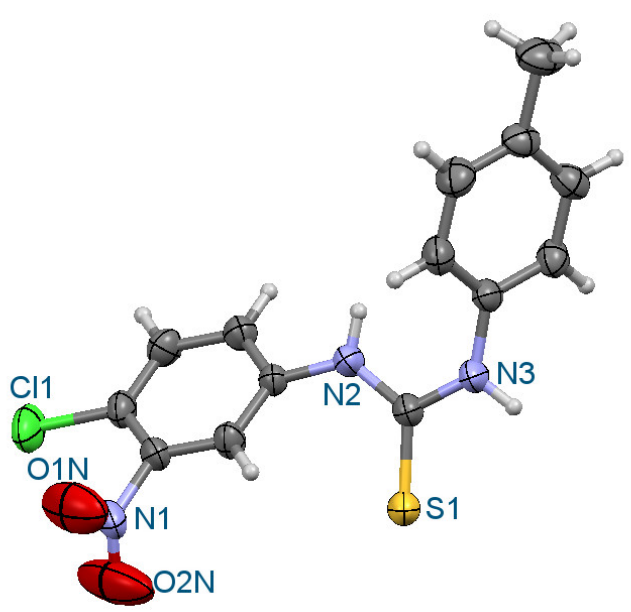

20 conformer cis-trans

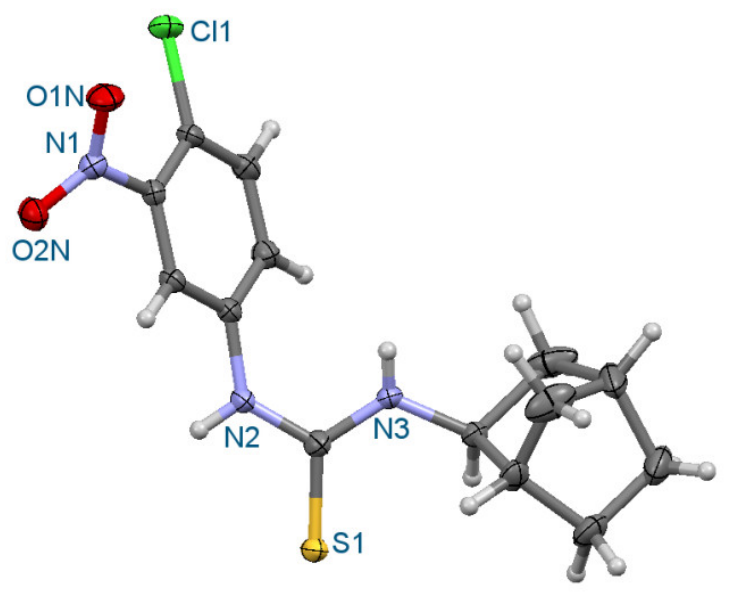

24 conformer trans-cis

Figure 1. Perspective view of molecules 20 and 24. Conformers are defined by relative orientation of 4-chloro-3-nitrophenyl and aryl/alkyl groups to thiourea $\mathrm{C}=\mathrm{S}$ bond.

\subsection{Cytotoxicity and Anti-HIV Activity}

Due to the previously reported anti-HIV activities of thiourea derivatives [11,43], both formerly $\mathbf{( 1 - 1 9 , 2 5 , 2 6 )}$ and newly synthesized compounds (20-24, 27-30) were tested in cell-based assay against the human immunodeficiency virus type-1 (HIV-1), using Efavirenz as the reference inhibitor. The cytotoxicity against MT-4 cells was evaluated in parallel with the antiviral activity (Table 1).

None of tested compounds showed selective antiviral activity against HIV-1. However, all compounds turned out interestingly cytotoxic for exponentially growing MT-4 cells, with many of them cytotoxic in the low micromolar range $\left(\mathrm{CC}_{50}<10 \mu \mathrm{M}\right)$. The antiproliferative activity against the $\mathrm{CD} 4+$ human $\mathrm{T}$ cell line derived from a hematological human tumor prompted us to evaluate the antiproliferative activity of a group of cytotoxic compounds $(1,4,6,9,10,11,13,14,17,19)$, also for a panel of other human and solid tumors, as well as for cell lines derived from normal human tissues (Table 4).

Interestingly, the tested compounds showed $\mathrm{CC}_{50}$ values comparable to that obtained with MT-4 cells, but they did not result highly selective, showing cytotoxicity also against the "normal" CRL7065 cell lines, even if with lower values. The highest selectivity versus CCRF-CEM and SK-MEL-28 cells was observed for 4-bromophenyl (6) and 4-iodophenylthiourea (17) derivatives. None of the tested compounds showed $\mathrm{CC}_{50}$ values comparable with Camptotecin, used as the reference compound. 
Table 4. Antiproliferative activity of selected compounds against human leukaemia/lymphoma, solid tumor and normal cell lines.

\begin{tabular}{cccccccc}
\hline \multirow{2}{*}{ Comp. } & MT-4 & CCRF-CEM & WIL-2NS & CCRF-SB & SK-MEL-28 & DU145 & CRL7065 \\
\cline { 2 - 7 } & \multicolumn{7}{c}{$\mathbf{1}^{\text {CC }} \mathbf{5 0}$} \\
\hline $\mathbf{1}$ & 8.8 & 13 & 14 & 14 & 8.7 & 7.6 & 18 \\
$\mathbf{4}$ & 9.6 & 22 & 30 & 22 & 15 & 8.0 & 20 \\
$\mathbf{6}$ & 6.6 & 6.0 & 7.0 & 8.0 & 6.0 & 6.0 & 30 \\
$\mathbf{9}$ & 7.0 & 9.1 & 11 & 9.4 & 20 & 8.4 & 22 \\
$\mathbf{1 0}$ & 7.3 & 5.0 & 7.0 & 8.8 & 6.6 & 6.5 & 16 \\
$\mathbf{1 1}$ & 7.9 & 8.0 & 9.9 & 8.6 & 8.5 & 6.0 & 16 \\
$\mathbf{1 3}$ & 8.0 & 4.0 & 7.6 & 6.7 & 6.0 & 7.0 & 16 \\
$\mathbf{1 4}$ & 8.2 & 9.4 & 10 & 9.8 & 9.0 & 7.8 & 18 \\
$\mathbf{1 7}$ & 7.8 & 6.0 & 7.0 & 8.3 & 6.0 & 11 & 30 \\
$\mathbf{1 9}$ & 8.2 & 9.1 & 10 & 9.2 & 9.0 & 8.0 & 20 \\
$*$ Ref & 0.004 & 0.003 & 0.005 & 0.004 & 0.07 & 0.08 & 0.3 \\
\hline
\end{tabular}

Data represent mean values for three independent determinations; ${ }^{1}$ Compound concentration $(\mu \mathrm{M})$ required to reduce cell proliferation by $50 \%$ under conditions allowing untreated controls to undergo at least three consecutive rounds of multiplication, as determined by the MTT method; * Ref.-Camptotecin.

\subsection{Cytotoxic Activity in HaCaT Cells}

The most promising antistaphylococcal $(\mathbf{1 1}, \mathbf{1 3})$ and antimycobacterial (25) agents among derivatives presented in our previous study [2] were now screened with respect to their toxicity against HaCaT cell line (health cell line from adult human skin). The HaCaT cell line was chosen, because it exhibits normal differentiation capacity, and its DNA fingerprint pattern is unaffected by long-term cultivations, transformations, and multiple chromosomal alterations [44].

Human keratinocyte cell lines were exposed to different concentrations of synthesized compounds for $24 \mathrm{~h}$. Derivatives were tested in concentrations equal to their cytotoxic concentrations against MT-4 cells (i.e., $8 \mu \mathrm{M}$ for $\mathbf{1 1}$ and $\mathbf{1 3}$, and $37 \mu \mathrm{M}$ for 25), as well as in concentrations 2 and 3 times higher. At the concentration $8 \mu \mathrm{M}$, the thiourea compound 11 caused approximately $20 \%$ decrease in cell viability, in comparison with controlled and untreated cells (Figure 2a), that indicated its weak cytotoxic influence against normal cells. On the other hand, cytotoxicity of antibacterial agents $\mathbf{1 3}$ and 25 observed at the level of 50\%, was found to be moderate according to ISO 10993-5 standards [45].

Results of the LDH (lactate dehydrogenase release) assay indicated that cell mortality in the presence of compounds $\mathbf{1 1}$ and $\mathbf{1 3}$ increased to $20 \%$ and $30 \%$, respectively (Figure $2 \mathrm{~b}$ ). The $\mathrm{LD}_{10}$ value (concentration at which $10 \%$ of cells were dead) was determined at the lowest investigated concentration of the compound $11(8 \mu \mathrm{M})$. Substance 13 at concentrations 8 and $16 \mu \mathrm{M}$ was found to be lowly cytotoxic, resulting in an approximate 10\% release of LDH. Compound 25 had the strongest impact on the mortality of tested cells, however, its concentration was the highest among all tested compounds $(37 \mu \mathrm{M})$. All applied concentrations of that derivative resulted in 7-fold higher cytotoxicity as compared to the $\mathrm{LD}_{10}$ value.

Significant concentration-dependent changes in shape, size, and density of $\mathrm{HaCaT}$ cells were observed under a light microscope after $24 \mathrm{~h}$ treatment with lowest concentrations of all investigated compounds (Figure 3). At given concentrations, derivatives inhibited viable cell proliferation by about $30-40 \%$ (compounds 13 and 25) or 65\% (11) (Figure 4). This suggests a direct effect on the HaCaT viability, which was confirmed by the MTT assay. Derivatives $\mathbf{1 3}$ and $\mathbf{2 5}$ have demonstrated an increased proliferation rate.

The tested substances modified cell viability as well as mortality and growth rate of $\mathrm{HaCaT}$ cultures. The presented results demonstrate that derivative 11, one of the strongest antistaphylococcal and antibiofilm agents, at its lowest concentration, possessed the lowest toxic effect on HaCaT cells. Our studies suggest that all tested substances in their lowest concentrations were less toxic in normal immortalized cell lines in comparison to cancer cell lines, however, further studies are needed to describe the underlining mechanism for future application. 
(a)

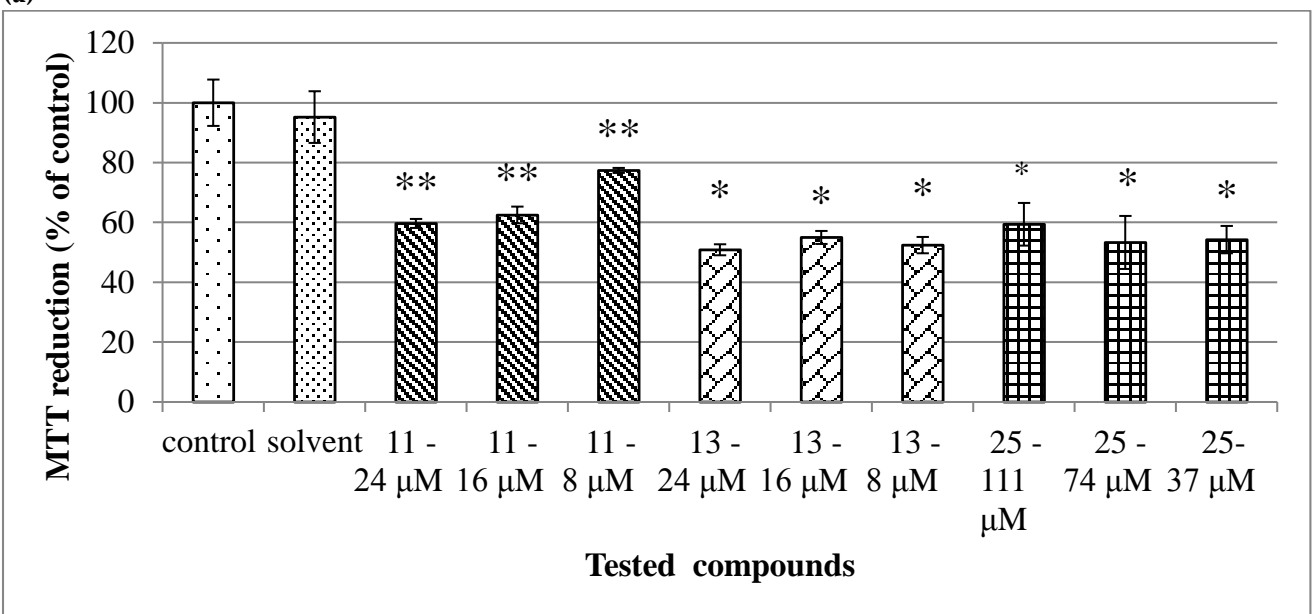

(b)

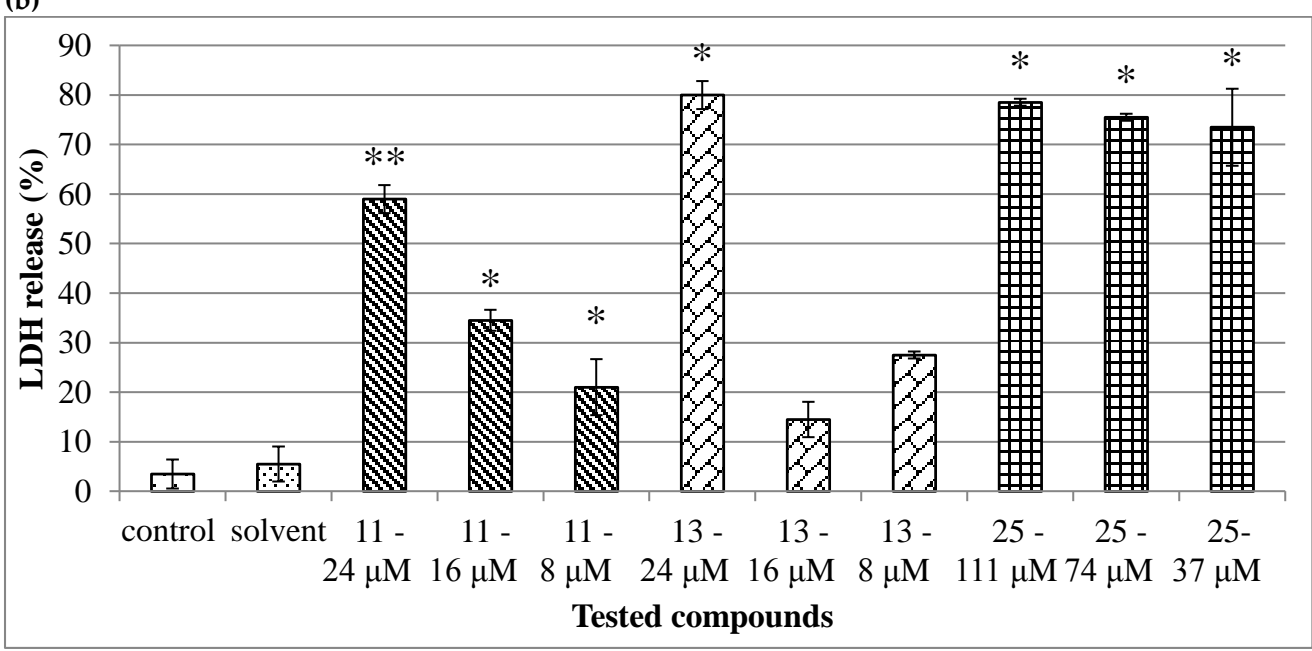

Figure 2. Cell viability assessed by MTT mitochondrial reduction (a), and LDH release (b) as a marker of cell death in HaCaT cells treated for $24 \mathrm{~h}$ with compounds 11, 13 and 25. Data are expressed as means \pm SD from three independent experiments performed in triplicate. Statistical significance: ${ }^{*} p<0.01$ and ** $p<0.001$ refer to the control (untreated) cells.

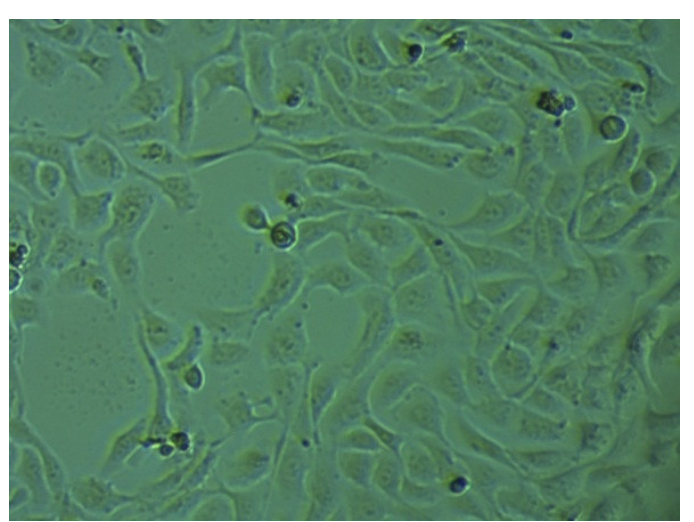

(a)

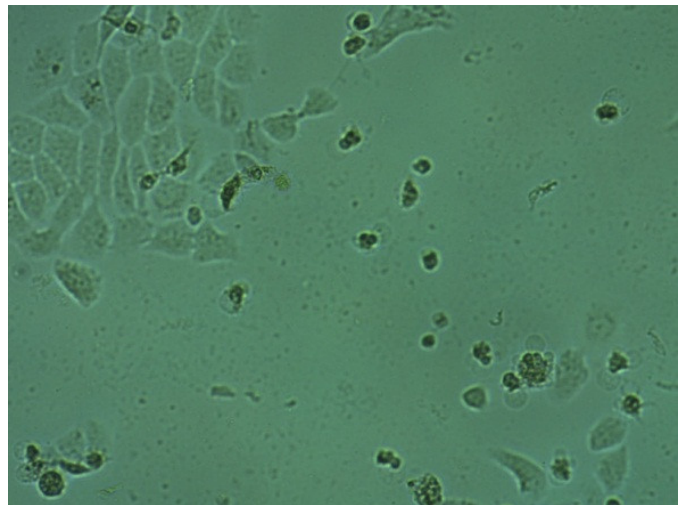

(b)

Figure 3. Cont. 


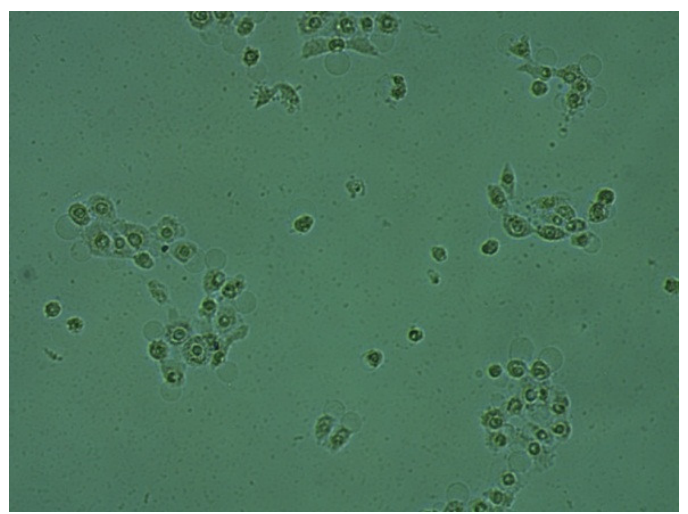

(c)

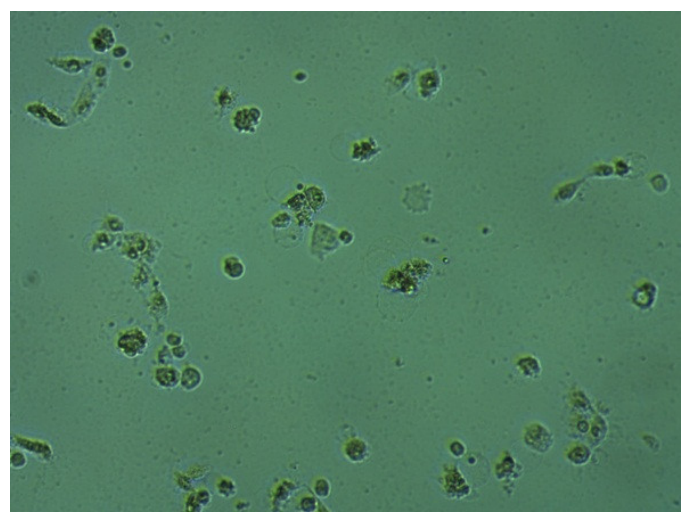

(d)

Figure 3. Morphological changes of HaCaT cells after $24 \mathrm{~h}$ treatment with compounds 11, 13 and 25, observed under the light microscope $(800 \times)$ : Untreated cells (a). Cells treated for $24 \mathrm{~h}$ with compounds 11, 13 and 25 in concentrations $8 \mu \mathrm{M}, 8 \mu \mathrm{M}$ and $37 \mu \mathrm{M}$, respectively (b-d).

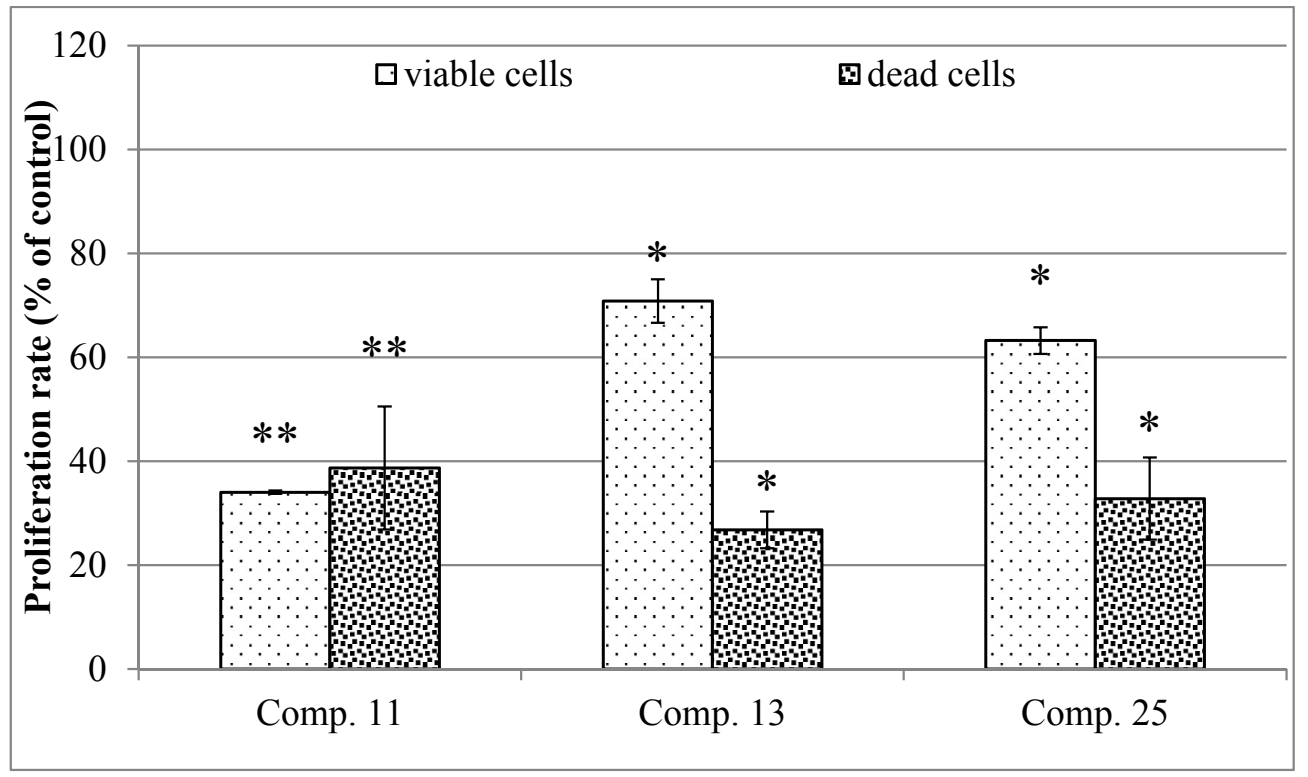

Figure 4. Proliferation rate assessment in $\mathrm{HaCaT}$ cells treated for $48 \mathrm{~h}$ with compounds 11, 13 and 25, applied at concentrations $8 \mu \mathrm{M}, 8 \mu \mathrm{M}$ and $37 \mu \mathrm{M}$, respectively. Data are expressed as means $\pm \mathrm{SD}$ from three independent experiments performed in triplicate. Statistical significance: ${ }^{*} p<0.01$ and ** $p<0.001$ refer to the control (untreated) cells.

\section{Materials and Methods}

\subsection{Chemistry}

All reagents and solvents were purchased from Alfa Aesar, Sigma Aldrich or POCh (Polskie Odczynniki Chemiczne, Gliwice, Poland). The infrared (IR) spectra were obtained on Perkin Elmer Spectrum 1000 spectrometer. The nuclear magnetic resonance (NMR) spectra were recorded on Varian VNMRS 300 Oxford NMR spectrometer, using tetramethylsilane (TMS) as the internal reference. Mass spectral electrospray ionization (ESI) measurements were carried out on Waters ZQ Micro-mass instruments with quadruple mass analyzer, at a declustering potential of 40-60 V. Flash chromatography was performed on Merck silica gel 60 (200-400 mesh) using chloroform eluent.

General procedure for the synthesis of (4-chloro-3-nitrophenyl)thiourea derivatives (20-24, 27-30)

To a solution of 4-chloro-3-nitroaniline $(0.0029 \mathrm{~mol} ; 0.5 \mathrm{~g})$ in dried acetonitrile $(10 \mathrm{~mL})$, a corresponding isothiocyanate $(0.0029 \mathrm{~mol})$ was added. The mixture was stirred at room temperature 
for $12 \mathrm{~h}$. Next the solvent was evaporated and the solid residue was either crystallized from acetonitrile (chloroform) or purified by column chromatography (chloroform).

The synthesis of derivatives 1-19, 25, 26 was published formerly [2].

1-(4-chloro-3-nitrophenyl)-3-(4-methylphenyl)thiourea (20)

Yield 30\%, yellow crystals, m.p. 156-158 ${ }^{\circ} \mathrm{C}$. FT-IR $\left(\mathrm{KBr}, \mathrm{cm}^{-1}\right)$ : 3326.2, $3196.1(v \mathrm{~N}-\mathrm{H})$; 3113.6, 3024.4 $(v$ ar C-H); $2977.6(v$ alC-H $) ; 1589.6(\delta$ N-H); $1533.8(v$ N-O); $1482.0(v$ arC-C); $1407.0(\delta$ ar(1,4)C-C); 1358.6 ( $\vee$ N-O); 1299.9 ( $\delta$ arC-H); 1236.4 ( $v$ alC-C); 1159.7, 1145.4 ( $\delta$ arC-H); 1043.3 ( $\vee \mathrm{C}=\mathrm{S}) ; 864.0$ ( $(\mathrm{C}-\mathrm{Cl}) ; 703.7$ ( $(\mathrm{C}=\mathrm{S}) .{ }^{1} \mathrm{H}$ NMR (300 MHz, DMSO) $\delta: 10.07-10.05(\mathrm{~m}, 2 \mathrm{H}, \mathrm{NH}), 8.35(\mathrm{~d}, 1 \mathrm{H}, J=2.7 \mathrm{~Hz}, \mathrm{H}-2), 7.80$ (dd, $\left.1 \mathrm{H}, J_{1}=2.4 \mathrm{~Hz}, J_{2}=2.7 \mathrm{~Hz}, \mathrm{H}-6\right), 7.69(\mathrm{~d}, 1 \mathrm{H}, J=8.7 \mathrm{~Hz}, \mathrm{H}-5), 7.34-7.29\left(\mathrm{~m}, 2 \mathrm{H}, \mathrm{H} 3^{\prime}, \mathrm{H}-5^{\prime}\right), 7.18-7.16(\mathrm{~d}$, $\left.2 \mathrm{H}, J=8.1 \mathrm{~Hz}, \mathrm{H}-2^{\prime}, \mathrm{H}^{-} 6^{\prime}\right), 2.29$ (s, 3H, H-4'a). ${ }^{13} \mathrm{C}$ NMR (75.4 MHz, DMSO) $\delta: 179.63$ (C=S), 146.78 (C-3), 139.86 (C-1), 136.13 (C-1'), 134.40 (C-4'), 131.20 (C-4), 129.13 (C-3', C-5'), 128.34 (C-5), 124.11 (C-2', C-6'), 119.69 (C-2), 119.28 (C-6), 20.52 (C-4'a). ESI MS: $m / z=320.0[\mathrm{M}-\mathrm{H}]^{-}$(100\%). Rf for TLC $\left(\mathrm{CHCl}_{3}: \mathrm{MeOH}\right.$ $(1 \%)): 0.12$.

Crystal data: crystal system triclinic, space group P-1, unit cell dimensions at $293 \mathrm{~K}: \mathrm{a}=7.442(1) \AA$, $\mathrm{b}=8.012(2) \AA, \mathrm{c}=12.944(3) \AA, \alpha=98.74(3)^{\circ}, \beta=94.81(3)^{\circ}, \gamma=100.17(3)^{\circ}, \mathrm{V}=746.0(3) \AA 3$, $\underline{Z}=2, D_{\text {calc }}=1.433 \mathrm{~g} / \mathrm{cm}^{3}, \mathrm{~F}(000)=332, \mu=3.647 \mathrm{~mm}^{-1}, \theta$ range $=3.48$ to $75.15^{\circ}$, reflections collected/independent/observed 3147/3042/957, max. and min. transmission 0.7118 and 0.4283; Goodness-of-fit on $\mathrm{F}^{3} 0.929$, final $\mathrm{R}$ indices [I $>2 \sigma \sigma \mathrm{I}$ )], R1 $=0.0479$, wR2 $=0.1266, \mathrm{R}$ indices (all data), $\mathrm{R} 1=0.2455, \mathrm{wR} 2=0.1857$, residual electron density max. $/ \mathrm{min} .0 .38$ and $-0.36 \mathrm{e}^{-3}$. CCDC No. 1849698.

1-(4-chloro-3-nitrophenyl)-3-(4-methoxyphenyl)thiourea (21)

Yield $28 \%$, yellow powder, m.p. $149-150.5^{\circ} \mathrm{C}$. FT-IR $\left(\mathrm{KBr}, \mathrm{cm}^{-1}\right)$ : 3241.8, $3201.5(v \mathrm{~N}-\mathrm{H}) ; 3056.2$ ( $v$ arC-H); $1588.4(\delta \mathrm{N}-\mathrm{H}) ; 1548.9(v \mathrm{~N}-\mathrm{O}) ; 1484.8(v$ arC-C); $1405.6(\delta \operatorname{ar}(1,4) \mathrm{C}-\mathrm{C}) ; 1345.5(v \mathrm{~N}-\mathrm{O}) ; 1241.5$ ( $\vee$ C-O-C); 1175.9, 1125.5 ( $\delta$ arC-H); 1038.3 ( $\vee \mathrm{C}=\mathrm{S}) ; 880.2$ ( $\delta \mathrm{C}-\mathrm{Cl}) ; 697.2(\vee \mathrm{C}=\mathrm{S}) .{ }^{1} \mathrm{H}$ NMR $(300 \mathrm{MHz}$, DMSO) $\delta: 9.98(\mathrm{~s}, 2 \mathrm{H}, \mathrm{NH}), 8.34(\mathrm{~d}, 1 \mathrm{H}, J=2.4 \mathrm{~Hz}, \mathrm{H}-2), 7.80\left(\mathrm{dd}, 1 \mathrm{H}, J_{1}=2.4 \mathrm{~Hz}, J_{2}=2.7 \mathrm{~Hz}, \mathrm{H}-6\right)$, $7.68(\mathrm{~d}, 1 \mathrm{H}, \mathrm{J}=8.7 \mathrm{~Hz}, \mathrm{H}-5), 7.34-7.29$ (m, 2H, H-3' $\left.{ }^{\prime} \mathrm{H}-5^{\prime}\right), 6.96-6.91$ (m, 2H, H-2', $\left.\mathrm{H}-6^{\prime}\right), 3.76$ (s, 3H,

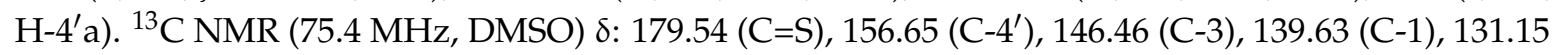
(C-1' $), 130.88$ (C-4), 128.06 (C-5), 125.88 (C-2' , C-6' $), 119.41$ (C-2), 118.93 (C-6), 113.61 (C-3' , C-5'), 54.97 (C-4'a). ESI MS: $m / z=336.0[\mathrm{M}-\mathrm{H}]^{-}(100 \%)$. Rf for TLC $\left(\mathrm{CHCl}_{3}: \mathrm{MeOH}(1 \%)\right): 0.17$.

1-(4-butyl-2-methylphenyl)-3-(4-chloro-3-nitrophenyl)thiourea (22)

Yield 40\%, dark yellow solid, m.p. $67-69{ }^{\circ} \mathrm{C}$. FT-IR $\left(\mathrm{KBr}, \mathrm{cm}^{-1}\right)$ : 3341.6, $3187.5(v \mathrm{~N}-\mathrm{H})$; $3098.1(v$ arC-H); 2954.5, $2859.9(v$ alC-H); $1584.5(\delta \mathrm{N}-\mathrm{H}) ; 1533.7(v \mathrm{~N}-\mathrm{O}) ; 1481.5(v$ arC-C); 1407.5 $(\delta \operatorname{ar}(1,4) \mathrm{C}-\mathrm{C}) ; 1342.5(\vee \mathrm{N}-\mathrm{O}) ; 1126.3\left(\delta\right.$ arC-H); $1045.6(\vee \mathrm{C}=\mathrm{S}) ; 872.3(\delta \mathrm{C}-\mathrm{Cl}) ; 715.2(\vee \mathrm{C}=\mathrm{S}) .{ }^{1} \mathrm{H}$ NMR (300 MHz, DMSO) $\delta: 9.95(\mathrm{~s}, 1 \mathrm{H}, \mathrm{NH}), 9.66(\mathrm{~s}, 1 \mathrm{H}, \mathrm{NH}), 8.36(\mathrm{~d}, 1 \mathrm{H}, J=2.1 \mathrm{~Hz}, \mathrm{H}-2), 7.82(\mathrm{dd}, 1 \mathrm{H}$, $\left.J_{1}=J_{2}=2.7 \mathrm{~Hz}, \mathrm{H}-6\right), 7.68(\mathrm{~d}, 1 \mathrm{H}, J=9.0 \mathrm{~Hz}, \mathrm{H}-5), 7.17-6.98\left(\mathrm{~m}, 3 \mathrm{H}, \mathrm{H}-3^{\prime}, \mathrm{H}-5^{\prime}, \mathrm{H}-6^{\prime}\right), 2.57-2.55(\mathrm{~m}$, $\left.2 \mathrm{H}, \mathrm{H}-4 \mathrm{a}^{\prime}\right), 2.20$ (s, 3H, H-2' a), 1.58-1.50 (m, 2H, H-4'b), 1.35-1.27 (m, 2H, H-4'c), 0.93-0.87 (m, 3H, H-4'd). ${ }^{13} \mathrm{C}$ NMR (75.4 MHz, DMSO) $\delta: 180.42$ (C=S), 146.69 (C-3), 141.03 (C-2'), 140.57 (C-4'), 139.92 (C-1), $134.53\left(\mathrm{C}-1^{\prime}\right), 131.14$ (C-4), $130.356\left(\mathrm{C}-3^{\prime}\right), 128.40$ (C-5), $127.65\left(\mathrm{C}-5^{\prime}\right), 126.16\left(\mathrm{C}-6^{\prime}\right), 119.74(\mathrm{C}-2)$, 119.26 (C-6), 34.35 (C-4'a), $33.04\left(C^{\prime}-4^{\prime} b\right), 21.77\left(C-4^{\prime} \mathrm{c}\right), 17.75$ (C-2'a), 13.76 (C-4'd). ESI MS: $m / z=376.1$ $[\mathrm{M}-\mathrm{H}]^{-}(100 \%)$. Rf for TLC $\left(\mathrm{CHCl}_{3}: \mathrm{MeOH}(1 \%)\right): 0.08$.

1-(4-chloro-3-nitrophenyl)-3-phenylthiourea (23)

Yield 56\%, pale yellow powder, m.p. $163-165^{\circ} \mathrm{C}$. FT-IR $\left(\mathrm{KBr}, \mathrm{cm}^{-1}\right)$ : 3323.5, $3161.3(v \mathrm{~N}-\mathrm{H}) ; 3089.6$, 2982.8 ( $v$ arC-H); $1592.0(\delta \mathrm{N}-\mathrm{H}) ; 1527.6$ ( $v$ N-O); $1482.0(v$ arC-C); 1407.5 ( $\delta$ ar(1,4)C-C); 1362.7 ( $v$ N-O); 1298.8, 1187.6, 1143.4 ( $\delta$ arC-H); 1047.1 ( $\vee \mathrm{C}=\mathrm{S}) ; 863.7$ ( $\delta \mathrm{C}-\mathrm{Cl}) ; 695.2(\vee \mathrm{C}=\mathrm{S}) .{ }^{1} \mathrm{H}$ NMR $(300 \mathrm{MHz}$, DMSO) $\delta: 10.15(\mathrm{~s}, 2 \mathrm{H}, \mathrm{NH}), 8.35(\mathrm{~d}, 1 \mathrm{H}, J=2.4 \mathrm{~Hz}, \mathrm{H}-2), 7.81\left(\mathrm{dd}, 1 \mathrm{H}, J_{1}=J_{2}=2.4 \mathrm{~Hz}, \mathrm{H}-6\right), 7.70$ $(\mathrm{d}, 1 \mathrm{H}, J=9.0 \mathrm{~Hz}, \mathrm{H}-5), 7.47-7.44\left(\mathrm{~m}, 2 \mathrm{H}, \mathrm{H}-2^{\prime}, \mathrm{H}-6^{\prime}\right), 7.37$ (t, $\left.2 \mathrm{H}, J=7.8 \mathrm{~Hz}, \mathrm{H}-3^{\prime}, \mathrm{H}-5^{\prime}\right), 7.18$ (t, 1H, $\left.J=7.35 \mathrm{~Hz}, \mathrm{H}-4^{\prime}\right) .{ }^{13} \mathrm{C}$ NMR (75.4 MHz, DMSO) $\delta: 179.95$ (C=S), 147.09 (C-3), 140.05 (C-1'), 139.08 
(C-1), 131.53 (C-4), $128.92\left(\mathrm{C}-3^{\prime}, \mathrm{C}^{\prime} 5^{\prime}\right), 128.62$ (C-5), 125.31 (C-4'), 124.20 (C-2' , C-6'), 119.98 (C-2), 119.65 (C-6). ESI MS: $m / z=330.0[\mathrm{M}+\mathrm{Na}]^{+}(100 \%)$. Rf for TLC $\left(\mathrm{CHCl}_{3}: \mathrm{MeOH}(1 \%)\right): 0.15$.

1-bicyclo[2.2.1]hept-2-yl-3-(4-chloro-3-nitrophenyl)thiourea (24)

Yield 30\%, dark yellow solid, m.p. $94-96{ }^{\circ} \mathrm{C}$. FT-IR $\left(\mathrm{KBr}, \mathrm{cm}^{-1}\right)$ : 3304.1, $3196.0(v \mathrm{~N}-\mathrm{H})$; 3033.5 ( $v$ arC-H); 2953.0, 2869.5 ( $v$ alC-H); $1576.1(\delta \mathrm{N}-\mathrm{H}) ; 1540.6(v \mathrm{~N}-\mathrm{O}) ; 1478.9(v$ arC-C); 1408.6 $(\delta \operatorname{ar}(1,4) \mathrm{C}-\mathrm{C}) ; 1343.4(\vee \mathrm{N}-\mathrm{O}) ; 1258.5,1133.8,1109.6$ ( $\delta \mathrm{arC}-\mathrm{H}) ; 1047.2(\vee \mathrm{C}=\mathrm{S}) ; 883.3$ ( $\delta \mathrm{C}-\mathrm{Cl}) ; 714.7$ ( $(\mathrm{C}=\mathrm{S}) .{ }^{1} \mathrm{H}$ NMR $(300 \mathrm{MHz}, \mathrm{DMSO}) \delta: 9.65(\mathrm{~s}, 1 \mathrm{H}, \mathrm{NH}), 8.47(\mathrm{~s}, 1 \mathrm{H}, \mathrm{NH}), 8.06(\mathrm{~m}, 1 \mathrm{H}, \mathrm{H}-2), 7.74$ $\left(\mathrm{dd}, 1 \mathrm{H}, J_{1}=J_{2}=2.4 \mathrm{~Hz}, \mathrm{H}-6\right), 7.65(\mathrm{~d}, 1 \mathrm{H}, J=9.0 \mathrm{~Hz}, \mathrm{H}-5), 3.98\left(\right.$ br. $\left.\mathrm{s}, 1 \mathrm{H}, \mathrm{H}-1^{\prime}\right), 2.29-2.26(\mathrm{~m}$, $\left.2 \mathrm{H}, \mathrm{H}-7^{\prime}\right), 1.77-1.70\left(\mathrm{~m}, 1 \mathrm{H}, \mathrm{H}-2^{\prime}\right), 1.54-1.30\left(\mathrm{~m}, 4 \mathrm{H}, \mathrm{H}-3^{\prime}, \mathrm{H}-6^{\prime}\right), 1.22-1.08\left(\mathrm{~m}, 3 \mathrm{H}, \mathrm{H}-4^{\prime}, \mathrm{H}-5^{\prime}\right) .{ }^{13} \mathrm{C}$ NMR (75.4 MHz, DMSO) 8: 178.76 (C=S), 146.20 (C-3), 139.47 (C-1), 130.68 (C-4), 126.10 (C-5), 117.27 (C-2, C-6), $56.34\left(\mathrm{C}-7^{\prime}\right), 40.97\left(\mathrm{C}-2^{\prime}, \mathrm{C}-6^{\prime}\right), 34.70\left(\mathrm{C}-5^{\prime}\right), 34.67\left(\mathrm{C}-1^{\prime}\right), 27.29\left(\mathrm{C}-4^{\prime}\right), 25.48\left(\mathrm{C}-3^{\prime}\right)$. ESI MS: $m / z=324.1[\mathrm{M}-\mathrm{H}]^{-}(100 \%)$. Rf for TLC $\left(\mathrm{CHCl}_{3}: \mathrm{MeOH}(1 \%)\right): 0.09$.

Crystal data: crystal system triclinic, space group P-1, unit cell dimensions at $120 \mathrm{~K}: \mathrm{a}=7.273(2) \AA$, $\mathrm{b}=9.652(2) \AA, \mathrm{c}=11.862(3) \AA, \alpha=105.57(2)^{\circ}, \beta=105.66(3)^{\circ}, \gamma=96.76(2)^{\circ}, \mathrm{V}=756.0(3) \AA^{3}$, $\mathrm{Z}=2, \mathrm{D}_{\text {calc }}=1.431 \mathrm{~g} / \mathrm{cm}^{3}, \mu=3.600 \mathrm{~mm}^{-1}, \mathrm{~F}(000)=340, \theta$ range 4.08 to $73.77^{\circ}$, reflections collected/independent/observed 10755/2994/2701; max. and min. transmission 1 and 0.75929; Goodness-of-fit on $\mathrm{F}^{2}$ 1.084, final $R$ indices $[\mathrm{I}>2 \sigma(\mathrm{I})] \mathrm{R} 1=0.0395, \mathrm{wR} 2=0.0943 ; R$ indices (all data) $\mathrm{R} 1=0.0456, \mathrm{wR} 2=0.0975$, residual electron density $\max / \min 0.45$ and $-0.54 \mathrm{e}^{-3}$. The cycloalkyl group, viz. 1-bicyclo[2.2.1]hept-2-yl, is disordered over two positions with the site occupancy factors being 0.64:0.36. CCDC No. 1849699.

1-(4-chloro-3-nitrophenyl)-3-(2-methylprop-2-en-1-yl)thiourea (27)

Yield 29\%, light brown powder, m.p. 96-98 ${ }^{\circ} \mathrm{C}$. FT-IR $\left(\mathrm{KBr}, \mathrm{cm}^{-1}\right)$ : 3336.7, $3198.9(v \mathrm{~N}-\mathrm{H})$; 3075.6, 3022.8 ( $\vee$ arC-H); $1652.3(\vee \mathrm{C}=\mathrm{C}) ; 1577.4(\delta \mathrm{N}-\mathrm{H}) ; 1535.1$ ( $\vee \mathrm{N}-\mathrm{O}) ; 1470.4(v$ arC-C, $\delta$ alC-H); 1407.5 $(\delta \operatorname{ar}(1,4) \mathrm{C}-\mathrm{C}) ; 1347.5$ ( $\vee \mathrm{N}-\mathrm{O}) ; 1312.2,1194.6,1140.4(\delta \mathrm{arC}-\mathrm{H}) ; 1040.5(\vee \mathrm{C}=\mathrm{S}) ; 882.0$ ( $\delta \mathrm{C}-\mathrm{Cl}) ; 683.2$ ( $\vee \mathrm{C}=\mathrm{S}) .{ }^{1} \mathrm{H}$ NMR $(300 \mathrm{MHz}, \mathrm{DMSO}) \delta: 9.99$ (br. s, $\left.1 \mathrm{H}, \mathrm{NH}\right), 8.42$ (br. s, $\left.1 \mathrm{H}, \mathrm{H}-2\right), 8.23$ (br. s, $1 \mathrm{H}, \mathrm{NH}$ ), $7.76\left(\mathrm{dd}, 1 \mathrm{H}, J_{1}=J_{2}=2.4 \mathrm{~Hz}, \mathrm{H}-6\right), 7.68(\mathrm{~d}, 1 \mathrm{H}, J=9.0 \mathrm{~Hz}, \mathrm{H}-5), 4.84\left(\mathrm{~s}, 2 \mathrm{H}, \mathrm{H}-3^{\prime}\right), 4.09$ (br. s, 2H, H-1'), 1.72 (s, 3H, H-2'a). ${ }^{13} \mathrm{C}$ NMR (75.4 MHz, DMSO) $\delta: 181.06$ (C=S), 147.07 (C-3), 141.78 (C-1), 140.09 (C-5), 131.60 (C-4), 127.49 (C-3'), 118.79 (C-2'), 110.78 (C-2, C-6), 49.19 (C-1'), 20.65 (C-2'a). ESI MS: $m / z=284.0[\mathrm{M}-\mathrm{H}]^{-}(100 \%)$. Rf for TLC $\left(\mathrm{CHCl}_{3}: \mathrm{MeOH}(1 \%)\right): 0.10$.

1-(4-chloro-3-nitrophenyl)-3-prop-2-en-1-ylthiourea (28)

Yield 31\%, pale yellow crystals, m.p. $112-114{ }^{\circ} \mathrm{C}$. FT-IR $\left(\mathrm{KBr}, \mathrm{cm}^{-1}\right)$ : 3370.1, $3173.8(v \mathrm{~N}-\mathrm{H}) ; 3072.7$, $3002.6(v$ arC-H, $v=\mathrm{C}-\mathrm{H}) ; 1641.6(v \mathrm{C}=\mathrm{C}) ; 1600.7(\delta \mathrm{N}-\mathrm{H}) ; 1534.5(v \mathrm{~N}-\mathrm{O}) ; 1471.6(v$ arC-C); 1431.1 $(\delta=\mathrm{C}-\mathrm{H}) ; 1409.4(\delta \operatorname{ar}(1,4) \mathrm{C}-\mathrm{C}) ; 1349.5(\delta$ alC-H, $\delta=\mathrm{C}-\mathrm{H}) ; 1311.5(v \mathrm{~N}-\mathrm{O}) ; 1195.9,1127.9(\delta \operatorname{arC}-\mathrm{H})$; $1041.4(\vee \mathrm{C}=\mathrm{S}) ; 839.4(\delta \mathrm{C}-\mathrm{Cl}) ; 711.5(\vee \mathrm{C}=\mathrm{S}) .{ }^{1} \mathrm{H}$ NMR $(300 \mathrm{MHz}, \mathrm{DMSO}) \delta: 9.97(\mathrm{~s}, 1 \mathrm{H}, \mathrm{NH}), 8.40(\mathrm{~d}$, $1 \mathrm{H}, J=2.1 \mathrm{~Hz}, \mathrm{H}-2), 8.24(\mathrm{~s}, 1 \mathrm{H}, \mathrm{NH}), 7.76\left(\mathrm{dd}, 1 \mathrm{H}, J_{1}=2.4 \mathrm{~Hz}, J_{2}=2.7 \mathrm{~Hz}, \mathrm{H}-6\right), 7.68(\mathrm{~d}, 1 \mathrm{H}, J=9.0 \mathrm{~Hz}$, $\mathrm{H}-5), 5.96-5.83\left(\mathrm{~m}, 1 \mathrm{H}, \mathrm{H}-2^{\prime}\right), 5.25-5.11\left(\mathrm{~m}, 2 \mathrm{H}, \mathrm{H}-3^{\prime}\right), 4.15\left(\mathrm{~m}, 2 \mathrm{H}, \mathrm{H}-\mathrm{-}^{\prime}\right) .{ }^{13} \mathrm{C}$ NMR (75.4 MHz, DMSO) $\delta: 180.52$ (C=S), 146.82 (C-3), 139.78 (C-1), 134.19 (C-5), 131.32 (C-4), 127.31 (C-3'), $118.64\left(\mathrm{C}-2^{\prime}\right), 116.08$ $(\mathrm{C}-2, \mathrm{C} 6), 46.02\left(\mathrm{C}-1^{\prime}\right)$. ESI MS: $m / z=270.0[\mathrm{M}-\mathrm{H}]^{-}(100 \%)$. Rf for TLC $\left(\mathrm{CHCl}_{3}: \mathrm{MeOH}(1 \%)\right): 0.11$.

1-(4-chloro-3-nitrophenyl)-3-[3-(methylsulfanyl)propyl]thiourea (29)

Yield 35\%, light brown powder, m.p. $102-103.5^{\circ} \mathrm{C}$. FT-IR $\left(\mathrm{KBr}, \mathrm{cm}^{-1}\right)$ : 3330.7, $3171.5(v \mathrm{~N}-\mathrm{H})$; 3070.3, 2999.3 ( $v$ arC-H); 2941.3, 2915.6 ( $v$ alC-H); 1572.8 ( $\delta$ N-H); 1531.5 ( $v$ N-O); 1475.5 ( $v$ arC-C); $1455.1(\delta$ alC-H); $1410.5(\delta$ ar(1,4)C-C); 1387.7 ( $\delta$ alC-H); 1351.8 ( $\vee$ N-O); 1298.9, 1154.7, $1134.1(\delta$ arC-H); 1043.6 ( $\vee \mathrm{C}=\mathrm{S}) ; 887.3$ ( $\delta \mathrm{C}-\mathrm{Cl}) ; 701.7$ ( $\vee \mathrm{C}=\mathrm{S}$ ). ${ }^{1} \mathrm{H}$ NMR (300 MHz, DMSO) $\delta: 9.88$ (br. s, 1H, NH), 8.37 $(\mathrm{d}, 1 \mathrm{H}, J=2.1 \mathrm{~Hz}, \mathrm{H}-2), 8.17$ (br. s, $1 \mathrm{H}, \mathrm{NH}), 7.73\left(\mathrm{dd}, 1 \mathrm{H}, J_{1}=J_{2}=1.8 \mathrm{~Hz}, \mathrm{H}-6\right), 7.67(\mathrm{~d}, 1 \mathrm{H}, J=8.7 \mathrm{~Hz}$, H-5), 3.56-3.54 (m, 2H, H-1'), 2.51-2.49 (m, 2H, H-3'), 2.06-2.05 (m, 3H, H-4'), 1.87-1.78 (m, 2H, H-2'). ${ }^{13} \mathrm{C}$ NMR (75.4 MHz, DMSO) 8: 179.85 (C=S), 146.25 (C-3), 139.24 (C-1), 130.78 (C-4), 126.57 (C-5), 
$117.86(\mathrm{C}-2, \mathrm{C}-6), 42.28\left(\mathrm{C}-1^{\prime}\right), 30.04\left(\mathrm{C}-2^{\prime}\right), 27.03\left(\mathrm{C}-3^{\prime}\right), 14.04\left(\mathrm{C}-4^{\prime}\right)$. ESI MS: $m / z=318.0[\mathrm{M}-\mathrm{H}]^{-}$ $(100 \%)$. Rf for TLC $\left(\mathrm{CHCl}_{3}: \mathrm{MeOH}(1 \%)\right): 0.09$.

1-(4-chloro-3-nitrophenyl)-3-(furan-2-ylmethyl)thiourea (30)

Yield 58\%, brown powder, m.p. $144-146^{\circ} \mathrm{C}$. FT-IR $\left(\mathrm{KBr}, \mathrm{cm}^{-1}\right)$ : 3299.1, $3180.4(v \mathrm{~N}-\mathrm{H}) ; 3009.7$ $(v \operatorname{arC}-\mathrm{H}) ; 1578.2(\delta \mathrm{N}-\mathrm{H}) ; 1537.3(v \mathrm{~N}-\mathrm{O}) ; 1478.9(v \operatorname{arC}-\mathrm{C}) ; 1448.8(\delta$ alC-H$) ; 1407.9(\delta \operatorname{ar}(1,4) \mathrm{C}-\mathrm{C}) ;$ $1364.3(\delta$ alC-H); $1339.2(v$ N-O); 1297.7, 1190.4, $1139.0(\delta$ arC-H); $1018.2(v \mathrm{C}=\mathrm{S}) ; 884.6(\delta \mathrm{C}-\mathrm{Cl}) ; 714.8$ ( $v \mathrm{C}=\mathrm{S}) .{ }^{1} \mathrm{H}$ NMR $(300 \mathrm{MHz}, \mathrm{DMSO}) \delta: 9.98(\mathrm{~s}, 1 \mathrm{H}, \mathrm{NH}), 8.49(\mathrm{~s}, 1 \mathrm{H}, \mathrm{NH}), 8.41(\mathrm{~d}, 1 \mathrm{H}, J=2.1 \mathrm{~Hz}, \mathrm{H}-2)$, $7.76\left(\mathrm{dd}, 1 \mathrm{H}, J_{1}=J_{2}=2.4 \mathrm{~Hz}, \mathrm{H}-6\right), 7.68(\mathrm{~d}, 1 \mathrm{H}, J=8.7 \mathrm{~Hz}, \mathrm{H}-5), 7.62-7.61\left(\mathrm{~m}, 1 \mathrm{H}, \mathrm{H}-5^{\prime}\right), 6.42(\mathrm{dd}, 1 \mathrm{H}$, $\left.J_{1}=2.1 \mathrm{~Hz}, J_{2}=1.8 \mathrm{~Hz}, \mathrm{H}-4^{\prime}\right), 6.35\left(\mathrm{~d}, 1 \mathrm{H}, J_{1}=3.3 \mathrm{~Hz}, \mathrm{H}-3^{\prime}\right), 4.73\left(\mathrm{~d}, 2 \mathrm{H}, J=5.1 \mathrm{~Hz}, \mathrm{H}-1^{\prime}\right) .{ }^{13} \mathrm{C} \mathrm{NMR}$ (75.4 MHz, DMSO) 8: 180.27 (C=S), 150.75 (C-2'), 146.55 (C-3), 142.09 (C-5'), 139.42 (C-1), 131.07 (C-4), 127.09 (C-5), 118.62 (C-2), $118.37(\mathrm{C}-6), 110.25\left(\mathrm{C}-4^{\prime}\right), 107.44\left(\mathrm{C}-3^{\prime}\right)$. ESI MS: $m / z=310.0[\mathrm{M}-\mathrm{H}]^{-}$ (100\%). Rf for TLC $\left(\mathrm{CHCl}_{3}: \mathrm{MeOH}(1 \%)\right): 0.15$.

The NMR spectra of compounds 20-24, 27-30 can be found in Supplementary Materials.

\subsection{X-ray Crystalography}

The X-ray diffraction intensities were measured for $\mathbf{2 0}$ and $\mathbf{2 4}$ on a SuperNova diffractometer with monochromatized $\mathrm{CuK} \alpha$ radiation $(\lambda=1.54184 \AA$ ). Data sets were collected using the $\omega$ scan technique. The programs CrysAlisPro [46] were used for data collection, cell refinement and data reduction; empirical absorption correction was applied using spherical harmonics implemented in SCALE3 ABSPACK scaling algorithm. The structure was solved by direct methods using SHELXS-97 and refined by the full-matrix least-squares on $F^{2}$ using the SHELXL-97 [47]. Non-hydrogen atoms were refined with anisotropic displacement parameters. Hydrogen atoms were positioned geometrically and allowed to ride on their parent atoms, with $U_{i s o}(\mathrm{H})=1.2 U_{e q}(\mathrm{C})$.

\subsection{In Vitro Evaluation of Antimicrobial Activity}

The antimicrobial activity of the compounds was tested on Gram-positive bacteria (Staphylococcus aureus NCTC 4163, Staphylococcus aureus ATCC 25923, Staphylococcus aureus ATCC 6538, Staphylococcus aureus ATCC 29213, Staphylococcus epidermidis ATCC 12228, Staphylococcus epidermidis ATCC 35984, Enterococcus faecalis ATCC 29212, Bacillus subtilis ATCC 6633, Bacillus cereus ATCC 11778, Micrococcus luteus ATCC 9341, Micrococcus luteus ATCC 10240); Gram-negative rods (Escherichia coli ATCC 10538, Escherichia coli ATCC 25922, Escherichia coli NCTC 8196, Proteus vulgaris NCTC 4635, Pseudomonas aeruginosa ATCC 15442, Pseudomonas aeruginosa NCTC 6749, Pseudomonas aeruginosa ATCC 27863, Bordetella bronchiseptica ATCC 4617) and yeasts (Candida albicans ATCC 10231, Candida albicans ATCC 90028, Candida parapsilosis ATCC 22019). Other microorganisms used were obtained from the collection of the Department of Pharmaceutical Microbiology, Medical University of Warsaw, Poland.

Antibacterial activity was examined by the disc-diffusion method under standard conditions using Mueller-Hinton II agar medium (Becton Dickinson) according to CLSI (previously NCCLS) guidelines [39]. Antifungal activities were assessed using Mueller-Hinton agar $+2 \%$ glucose and $0.5 \mu \mathrm{g} / \mathrm{mL}$ Methylene Blue Dye Medium [40]. Sterile filter paper discs (9 mm diameter, Whatman No 3 chromatography paper) were dripped with tested compound solutions (in DMSO) to load $400 \mu \mathrm{g}$ of a given compound per disc. Dry discs were placed on the surface of appropriate agar medium. The results (diameter of the growth inhibition zone) were read after $18 \mathrm{~h}$ of incubation at $35^{\circ} \mathrm{C}$. Minimal Inhibitory Concentration (MIC) was tested by the twofold serial microdilution method (in 96-well microtiter plates) using Mueller-Hinton Broth medium (Beckton Dickinson) for bacteria or RPMI-1640 medium for Candida species according to CLSI guidelines [41,42]. The stock solution of tested agent was prepared in DMSO and diluted in sterile water. Concentrations of tested agents ranged from 0.125 to $512 \mu \mathrm{g} / \mathrm{mL}$. The final inoculum of all studied microorganisms was $10^{5} \mathrm{CFU} / \mathrm{mL}^{-1}$ (colony forming units per $\mathrm{mL}$ ). Minimal inhibitory concentrations (the lowest concentration of a tested agent 
that prevents visible growth of a microorganism) were read after $18 \mathrm{~h}$ (bacteria) or $24 \mathrm{~h}$ (yeasts) of incubation at $35^{\circ} \mathrm{C}$.

\subsection{Cytotoxicity and Anti-HIV Assays}

Cell line supporting the multiplication of Human Immunodeficiency Virus type-1 (HIV-1) was the CD4+ human T-cells, derived from human hematological tumors, containing an integrated HTLV-1 genome (MT-4). Cells were purchased from American Type Culture Collection (ATCC). Human Immunodeficiency Virus type-1 (HIV-1) IIIB laboratory strain was obtained from the supernatant of the persistently infected H9/IIIB cells (NIH 1983).

Exponentially growing MT- 4 cells were seeded at an initial density of $1 \times 10^{5}$ cells $/ \mathrm{mL}$ in 96-well plates in RPMI-1640 medium, supplemented with 10\% fetal bovine serum (FBS), 100 units /mL penicillin $\mathrm{G}$ and $100 \mu \mathrm{g} / \mathrm{mL}$ streptomycin. Cell cultures were then incubated at $37^{\circ} \mathrm{C}$ in a humidified, $5 \% \mathrm{CO}_{2}$ atmosphere, in the absence or presence of serial dilutions of tested compounds. Cell viability was determined after $96 \mathrm{~h}$ at $37^{\circ} \mathrm{C}$ by the 3-(4,5-dimethylthiazol-2-yl)-2,5-diphenyl-tetrazolium bromide (MTT) method.

The activity of compounds against HIV-1 was based on inhibition of virus-induced cytopathogenicity in MT- 4 cell acutely infected with a multiplicity of infection (m.o.i.) of 0.01 . Briefly, $50 \mu \mathrm{L}$ of RPMI containing $1 \times 10^{4}$ MT- 4 cells were added to each well of flat-bottom microtiter trays, containing $50 \mu \mathrm{L}$ of RPMI without or with serial dilutions of test compounds. Then, $20 \mu \mathrm{L}$ of a HIV-1 suspension containing 100 $\mathrm{CCID}_{50}$ were added. After a 4-day incubation at $37^{\circ} \mathrm{C}$, cell viability was determined by the MTT method.

\subsection{Antiproliferative Assays}

Cell lines derived from human hematological tumors were: CD4+ human T-cells containing an integrated HTLV-1 genome (MT-4); CD4+ human acute T-lymphoblastic leukemia (CCRF-CEM); human splenic B-lymphoblastoid cells (WIL-2NS); human acute B-lymphoblastic leukemia (CCRF-SB). Cells were seeded at an initial density of $1 \times 10^{5}$ cells $/ \mathrm{mL}$ in 96 well plates in RPMI-1640 medium supplemented with $10 \%$ fetal calf serum (FCS), 100 units $/ \mathrm{mL}$ penicillin $\mathrm{G}$ and $100 \mu \mathrm{g} / \mathrm{mL}$ streptomycin.

Cell lines derived from human solid tumors were: Skin melanoma (SK-MEL-28); prostate carcinoma (DU-145). Normal tissues foreskin fibroblasts (CRL-7065) were also used. Cells were seeded at $1 \times 10^{5}$ cells $/ \mathrm{mL}$ in 96 well plates in specific media supplemented with $10 \%$ FCS and antibiotics, as above. Cell cultures were then incubated at $37^{\circ} \mathrm{C}$ in a humidified, $5 \% \mathrm{CO}_{2}$ atmosphere in the absence or presence of serial dilutions of test compounds. Cell viability was determined after $96 \mathrm{~h}$ at $37^{\circ} \mathrm{C}$ by the MTT method.

\subsection{Cytotoxic Activity in HaCaT Cells}

\subsubsection{Cell Culture: Conditions and Treatments}

Human immortal keratinocyte cell line from adult human skin (HaCaT) was purchased from American Type Culture Collection (Rockville, MD, USA), and cultured in Dulbecco's Modified Eagle's Medium (DMEM), supplemented with antibiotics (penicillin and streptomycin), $10 \%$ heat-inactivated FBS-fetal bovine serum (Gibco Life Technologies, Carlsbad, CA, USA) at $37^{\circ} \mathrm{C}$ and $5 \% \mathrm{CO}_{2}$ atmosphere. Cells were passaged using trypsin-EDTA (Gibco Life Technologies, Carlsbad, CA, USA) and cultured in 24-well plates $\left(2.5 \times 10^{4}\right.$ cells per well). Experiments were conducted in DMEM with $2 \%$ FBS.

\subsubsection{Cell Viability Assessment (Mitochondrial Function Assessment)}

The cell viability assay was assessed by the determination of MTT salt (3-(4,5-dimethylthiazol2-yl)-2,5-diphenyltetrazolium bromide, Sigma-Aldrich Chemie, Buchs, Germany) conversion by mitochondrial dehydrogenase. The cells were incubated for $24 \mathrm{~h}$ in 24 -well plates with tested compounds (11, 13 and 25) at given concentrations, and subsequently for another $2 \mathrm{~h}$ with $0.5 \mathrm{mg} / \mathrm{mL}$ of MTT solution, which was converted in living cells under the effect of mitochondrial dehydrogenase 
into insoluble formazan. Then the converted dye was solubilized with the use of $0.04 \mathrm{M} \mathrm{HCl}$ in absolute isopropanol. Absorbance of solubilized formazan was measured spectrophotometrically at $570 \mathrm{~nm}$ (using Epoch microplate reader, BioTek Inc., Winooski, VT, USA, equipped with Gen 5 software (BioTech Instruments, Inc., Biokom, Janki, Polska).

Cell viability was presented as a percent of MTT in the treated cells versus the control (cells incubated in serum-free DMEM without extracts). The relative MTT level (\%) was calculated as $[A] /[B]$ $\times 100$, where $[\mathrm{A}]$ is the absorbance of the test sample and $[\mathrm{B}]$ is the absorbance of the control sample containing the untreated cells. The decreased relative MTT level indicates decreased cell viability.

\subsubsection{Lactate Dehydrogenase Release Assay (Cellular Membrane Integrity Assessment)}

Release of lactate dehydrogenase (LDH) from the cytosol to culture medium is a marker of cell death. The assay was performed after $24 \mathrm{~h}$ incubation of HaCaT cells in 24-well plates with investigated concentrations of each compound. The activity of LDH released from the cytosol of damaged cells to the supernatant was measured using the protocol of the cytotoxicity detection kit LDH test described by the manufacturer (Roche Diagnostics, Berlin, Germany). Absorbance was measured at $490 \mathrm{~nm}$ using a microplate reader (using Epoch microplate reader, BioTek Inc., Winooski, VT, USA) equipped with Gen5 software (BioTech Instruments, Inc., Biokom, Janki, Polska)

Compounds mediated cytotoxicity expressed as the LDH release (\%) was determined by the following equation: [(A test sample-A low control)/(A high control-A low control)] $\times 100 \%$ (A-absorbance); where "low control" were cells in DMEM with 2\% FBS without tested compounds, and "high control" were cells incubated in DMEM with 2\% FBS with 10\% Triton X-100 (100\% LDH release).

\subsubsection{Proliferation Rate in Cultures of HaCaT Cells}

After $48 \mathrm{~h}$ incubation with the lowest concentration of the tested compound the increased number of viable cells were assessed by direct counting of cells using trypan blue with a Countess Automated Cell Counter (Invitrogen, Carlsbad, CA, USA). The results are presented as a \% of viable and dead cells versus control.

\section{Conclusions}

To sum up, this work has revealed the synthesis of new thiourea derivatives and their in vitro antibacterial activity against clinically relevant pathogens. The title compounds showed potent to moderate antimicrobial activity. Representative aryl-thioureas 20, 22, 23 and bicyclic-thiourea derivative $\mathbf{2 4}$ were even more active towards selected clinical staphylococci than the reference drug, Ciprofloxacin. To complete the biological profile of the presented thiourea series, their cytotoxic activities in MT-4 cells, as well as human hematological and solid tumors cell lines were assessed. Several compounds $(1,4,6,9-11,13,14,17,19)$ turned out cytotoxic in the low micromolar range $\left(\mathrm{CC}_{50}<10 \mu \mathrm{M}\right)$. Performed studies proved that synthesized derivatives weakly to moderately influenced the viability and growth of the human immortal keratinocyte cell line (HaCaT).

Supplementary Materials: Supplementary materials can be found online. The experimental details and final atomic parameters for $\mathbf{2 0}$ and $\mathbf{2 4}$ have been deposited with the Cambridge Crystallographic Data Centre as supplementary material (CCDC ID: 1849698 and 1849698, respectively). Copies of the data can be obtained free of charge on request via www.ccdc.cam.ac.uk/data_request/cif, or by emailing data_request@ccdc.cam.ac.uk, or by contacting The Cambridge Crystallographic Data Centre, 12, Union Road, Cambridge CB2 1EZ, UK; fax: +44 1223336033.

Author Contributions: Conceptualization, A.B. and G.S.; Methodology, J.S.; Software, A.E.K.; Validation, A.C. and P.S.-Ł.; Formal Analysis, S.M.; Investigation, G.S.; S.M.; G.G.; Resources, J.S.; Data Curation, A.E.K. and O.S.; Writing-Original Draft Preparation, A.B. and G.G.; Writing-Review \& Editing, A.B.; Visualization, P.S.-Ł.; Supervision, M.S.; Project Administration, M.S.; Funding Acquisition, G.K.-T. 
Funding: This work was supported by the Medical University of Warsaw and carried out with the use of CePT infrastructure financed by the European Union-the European Regional Development Fund within the Operational Programme Innovative Economy for 2007-2013. The research was carried out with the facilities purchased thanks to the financial support of the European Regional Development Fund in the framework of the Operational Program Development of Eastern Poland 2007-2013 (Contract No. POPW.01.03.00-06-009/11-00, Equipping the laboratories of the Faculties of Biology and Biotechnology, Mathematics, Physics and Informatics, and Chemistry for studies of biologically active substances and environmental samples.

Acknowledgments: Authors would like to thank Sylwester Krukowski from the Department of Inorganic and Analytical Chemistry, Faculty of Pharmacy, Medical University of Warsaw, for recording the IR spectra.

Conflicts of Interest: The authors declare no conflict of interest. The funders had no role in the design of the study; in the collection, analyses, or interpretation of data; in the writing of the manuscript, and in the decision to publish the results.

\section{References}

1. Bielenica, A.; Stefańska, J.; Stępień, K.; Napiórkowska, A.; Augustynowicz-Kopeć, E.; Sanna, G.; Madeddu, S.; Boi, S.; Giliberti, G.; Wrzosek, M.; et al. Synthesis, cytotoxicity and antimicrobial activity of thiourea derivatives incorporating 3-(trifluoromethyl)phenyl moiety. Eur. J. Med. Chem. 2015, 101, 111-125. [CrossRef] [PubMed]

2. Bielenica, A.; Stępień, K.; Napiórkowska, A.; Augustynowicz-Kopeć, E.; Krukowski, S.; Włodarczyk, M.; Struga, M. Synthesis and antimicrobial activity of 4-chloro-3-nitrophenylthiourea derivatives targeting bacterial type II topoisomerases. Chem. Biol. Drug Des. 2016, 87, 905-917. [CrossRef] [PubMed]

3. Foley, T.L.; Rai, G.; Yasgar, A.; Daniel, T.; Baker, H.L.; Attene-Ramos, M.; Kosa, N.M.; Leister, W.; Burkart, M.D.; Jadhav, A.; et al. 4-(3-Chloro-5-(trifluoromethyl)pyridin-2-yl)-N-(4-methoxypyridin-2-yl)piperazine-1-carbothioamide (ML267), a potent inhibitor of bacterial phosphopantetheinyl transferase that attenuates secondary metabolism and thwarts bacterial growth. J. Med. Chem. 2014, 57, 1063-1078. [CrossRef] [PubMed]

4. Madabhushi, S.; Mallu, K.K.; Vangipuram, V.S.; Kurva, S.; Poornachandra, Y.; Ganesh Kumar, C. Synthesis of novel benzimidazole functionalized chiral thioureas and evaluation of their antibacterial and anticancer activities. Bioorg. Med. Chem. Lett. 2014, 24, 4822-4825. [CrossRef] [PubMed]

5. Ghorab, M.M.; Alsaid, M.S.; El-Gaby, M.S.A.; Elaasser, M.M.; Nissan, Y.M. Antimicrobial and anticancer activity of some novel fluorinated thiourea derivatives carrying sulfonamide moieties: Synthesis, biological evaluation and molecular docking. Chem. Cent. J. 2017, 11, 1-14. [CrossRef] [PubMed]

6. Ghorab, M.M.; Alsaid, M.S.; El-Gaby, M.S.A.; Safwat, N.A.; Elaasser, M.M.; Soliman, A.M. Biological evaluation of some new N-(2,6-dimethoxypyrimidinyl) thioureido benzenesulfonamide derivatives as potential antimicrobial and anticancer agents. Eur. J. Med. Chem. 2016, 124, 299-310. [CrossRef] [PubMed]

7. Medapi, B.; Renuka, J.; Saxena, S.; Sridevi, J.P.; Medishetti, R.; Kulkarni, P.; Yogeeswari, P.; Sriram, D. Design and synthesis of novel quinoline-aminopiperidine hybrid analogues as Mycobacterium tuberculosis DNA gyraseB inhibitors. Bioorg. Med. Chem. 2015, 23, 2062-2078. [CrossRef] [PubMed]

8. Sriram, D.; Yogeeswari, P.; Dinakaran, M.; Thirumurugan, R. Antimycobacterial activity of novel 1-(5-cyclobutyl1,3-oxazol-2-yl)-3-(sub)phenyl/pyridylthiourea compounds endowed with high activity toward multidrugresistant Mycobacterium tuberculosis. J. Antimicrob. Chemother. 2007, 59, 1194-1196. [CrossRef] [PubMed]

9. Bielenica, A.; Sanna, G.; Madeddu, S.; Struga, M.; Jóźwiak, M.; Kozioł, A.E.; Sawczenko, A.; Materek, I.B.; Serra, A.; Giliberti, G. New thiourea and 1,3-thiazolidin-4-one derivatives effective on the HIV-1 virus. Chem. Biol. Drug Des. 2017, 90, 883-891. [CrossRef] [PubMed]

10. D'Cruz, O.J.; Qazi, S.; Yiv, S.; Uckun, F.M. A novel vaginal microbicide containing the rationally designed anti-HIV compound HI-443 (N'-[2-(2-thiophene)ethyl]- $N^{\prime}$-[2-(5-bromopyridyl)] thiourea]). Expert Opin. Investig. Drugs 2012, 21, 265-279. [CrossRef] [PubMed]

11. Karakuş, S.; Güniz Küçükgüzel, S.; Küçükgüzel, I.; De Clercq, E.; Pannecouque, C.; Andrei, G.; Snoeck, R.; Sahin, F.; Bayrak, O.F. Synthesis, antiviral and anticancer activity of some novel thioureas derived from N-(4-nitro-2-phenoxyphenyl)-methanesulfonamide. Eur. J. Med. Chem. 2009, 44, 3591-3595. [CrossRef] [PubMed] 
12. Bloom, J.D.; Dushin, R.G.; Curran, K.J.; Donahue, F.; Norton, E.B.; Terefenko, E.; Jones, T.R.; Ross, A.A.; Feld, B.; Lang, S.A.; et al. Thiourea inhibitors of herpes viruses. Part 2: $N$-Benzyl- $N$-arylthiourea inhibitors of CMV. Bioorg. Med. Chem. Lett. 2004, 14, 3401-3406. [CrossRef] [PubMed]

13. Bielenica, A.; Kędzierska, E.; Koliński, M.; Kmiecik, S.; Koliński, A.; Fiorino, F.; Severino, B.; Magli, E.; Corvino, A.; Rossi, I.; et al. 5-HT2 receptor affinity, docking studies and pharmacological evaluation of a series of 1,3-disubstituted thiourea derivatives. Eur. J. Med. Chem. 2016, 116, 173-186. [CrossRef] [PubMed]

14. Stefanska, J.; Szulczyk, D.; Koziol, A.E.; Miroslaw, B.; Kedzierska, E.; Fidecka, S.; Busonera, B.; Sanna, G.; Giliberti, G.; La Colla, P.; et al. Disubstituted thiourea derivatives and their activity on CNS: Synthesis and biological evaluation. Eur. J. Med. Chem. 2012, 55, 205-213. [CrossRef] [PubMed]

15. Bielenica, A.; Kedzierska, E.; Fidecka, S.; Maluszynska, H.; Miroslaw, B.; Koziol, A.E.; Stefanska, J.; Madeddu, S.; Giliberti, G.; Sanna, G.; et al. Synthesis, Antimicrobial and Pharmacological Evaluation of Thiourea derivatives of 4H-1,2,4-triazole. Lett. Drug Discov. Dev. 2015, 12, 263-276. [CrossRef]

16. Karakus, S.; Koçyigit-Kaymakcioglu, B.; Toklu, H.Z.; Aricioglu, F.; Rollas, S. Synthesis and anticonvulsant activity of new $N$-(alkyl/sub-stituted aryl)- $N^{\prime}$-[4-(5-cyclohexylamino)-1,3,4-thiadiazole-2-yl)phenyl]thioureas. Arch. Pharm. Weinheim 2009, 342, 48-53. [CrossRef] [PubMed]

17. Tokala, R.; Bale, S.; Janrao, I.P.; Vennela, A.; Kumar, N.P.; Senwar, K.R.; Godugu, C.; Shankaraiah, N. Synthesis of 1,2,4-triazole-linked urea/thiourea conjugates as cytotoxic and apoptosis inducing agents. Bioorg. Med. Chem. Lett. 2018, 28, 1919-1924. [CrossRef] [PubMed]

18. Shankaraiah, N.; Kumar, N.P.; Amula, S.B.; Nekkanti, S.; Jeengar, M.K.; Naidu, V.G.; Reddy, T.S.; Kamal, A. One-pot synthesis of podophyllotoxin-thiourea congeners by employing $\mathrm{NH}_{2} \mathrm{SO}_{3} \mathrm{H} / \mathrm{NaI}$ : Anticancer activity, DNA topoisomerase-II inhibition, and apoptosis inducing agents. Bioorg. Med. Chem. Lett. 2015, 25, 4239-4244. [CrossRef] [PubMed]

19. Sun, Y.; Shan, Y.; Li, C.; Si, R.; Pan, X.; Wang, B.; Zhang, J. Discovery of novel anti-angiogenesis agents. Part 8: Diaryl thiourea bearing $1 \mathrm{H}$-indazole-3-amine as multi-target RTKs inhibitors. Eur. J. Med. Chem. 2017, 141, 373-385. [CrossRef] [PubMed]

20. Turan-Zitouni, G.; Altıntop, M.D.; Özdemir, A.; Kaplancıklı, Z.A.; Çiftçi, G.A.; Temel, H.E. Synthesis and evaluation of bis-thiazole derivatives as new anticancer agents. Eur. J. Med. Chem. 2016, 107, 288-294. [CrossRef] [PubMed]

21. Koca, İ.; Özgür, A.; Er, M.; Gümüş, M.; Açikalin Coşkun, K.; Tutar, Y. Design and synthesis of pyrimidinyl acyl thioureas as novel Hsp90 inhibitors in invasive ductal breast cancer and its bone metastasis. Eur. J. Med. Chem. 2016, 122, 280-290. [CrossRef] [PubMed]

22. Mowafy, S.; Galanis, A.; Doctor, Z.M.; Paranal, R.M.; Lasheen, D.S.; Farag, N.A.; Jänne, P.A.; Abouzid, K.A. Toward discovery of mutant EGFR inhibitors; Design, synthesis and in vitro biological evaluation of potent 4-arylamino-6-ureido and thioureido-quinazoline derivatives. Bioorg. Med. Chem. 2016, 24, 3501-3512. [CrossRef] [PubMed]

23. Hamed, M.M.; Darwish, S.S.; Herrmann, J.; Abadi, A.H.; Engel, M. First Bispecific Inhibitors of the Epidermal Growth Factor Receptor Kinase and the NF-kB Activity as Novel Anticancer Agents. J. Med. Chem. 2017, 60, 2853-2868. [CrossRef] [PubMed]

24. Shing, J.C.; Choi, J.W.; Chapman, R.; Schroeder, M.A.; Sarkaria, J.N.; Fauq, A.; Bram, R.J. A novel synthetic 1,3-phenyl bis-thiourea compound targets microtubule polymerization to cause cancer cell death. Cancer Biol. Ther. 2014, 15, 895-905. [CrossRef] [PubMed]

25. Ma, L.Y.; Zheng, Y.C.; Wang, S.Q.; Wang, B.; Wang, Z.R.; Pang, L.P.; Zhang, M.; Wang, J.W.; Ding, L.; Li, J.; et al. Design, synthesis, and structure-activity relationship of novel LSD1 inhibitors based on pyrimidine-thiourea hybrids as potent, orally active antitumor agents. J. Med. Chem. 2015, 58, 1705-1716. [CrossRef] [PubMed]

26. Suzuki, T.; Miyata, N. Lysine demethylases inhibitors. J. Med. Chem. 2011, 54, 8236-8250. [CrossRef] [PubMed]

27. Ghorab, M.M.; Alsaid, M.S.; Al-Dosary, M.S.; Nissan, Y.M.; Attia, S.M. Design, synthesis and anticancer activity of some novel thioureido-benzenesulfonamides incorporated biologically active moieties. Chem. Cent. J. 2016, 10, 1-13. [CrossRef] [PubMed]

28. Lin, S.; Lombardo, M.; Malkani, S.; Hale, J.J.; Mills, S.G.; Chapman, K.; Thompson, J.E.; Zhang, W.X.; Wang, R.; Cubbon, R.M.; et al. Novel 1-(2-aminopyrazin-3-yl)methyl-2-thioureas as potent inhibitors of mitogen-activated protein kinase-activated protein kinase 2 (MK-2). Bioorg. Med. Chem. Lett. 2009, 19, 3238-3242. [CrossRef] [PubMed] 
29. Kožurková, M.; Sabolová, D.; Kristian, P. A review on acridinylthioureas and its derivatives: Biological and cytotoxic activity. J. Appl. Toxicol. 2017, 37, 1132-1139. [CrossRef] [PubMed]

30. Repich, H.H.; Orysyk, V.V.; Palchykovska, L.G.; Orysyk, S.I.; Zborovskii, Y.L.; Vasylchenko, O.V.; Storozhuk, O.V.; Biluk, A.A.; Nikulina, V.V.; Garmanchuk, L.V.; et al. Synthesis, spectral characterization of novel Pd(II), $\mathrm{Pt}(\mathrm{II}) \pi$-coordination compounds based on $\mathrm{N}$-allylthioureas. Cytotoxic properties and DNA binding ability. J. Inorg. Biochem. 2017, 168, 98-106. [CrossRef] [PubMed]

31. Correa, R.S.; de Oliveira, K.M.; Delolo, F.G.; Alvarez, A.; Mocelo, R.; Plutin, A.M.; Cominetti, M.R.; Castellano, E.E.; Batista, A.A. Ru(II)-based complexes with $N$-(acyl)- $N^{\prime}, N^{\prime}$-(disubstituted)thiourea ligands: Synthesis, characterization, BSA- and DNA-binding studies of new cytotoxic agents against lung and prostate tumour cells. J. Inorg. Biochem. 2015, 150, 63-71. [CrossRef] [PubMed]

32. Plutín, A.M.; Mocelo, R.; Alvarez, A.; Ramos, R.; Castellano, E.E.; Cominetti, M.R.; Graminha, A.E.; Ferreira, A.G.; Batista, A.A. On the cytotoxic activity of $\mathrm{Pd}(\mathrm{II})$ complexes of $N, N$-disubstituted- $N^{\prime}$-acyl thioureas. J. Inorg. Biochem. 2014, 134, 76-82. [CrossRef] [PubMed]

33. Liu, S.; Louie, M.C.; Rajagopalan, V.; Zhou, G.; Ponce, E.; Nguyen, T.; Green, L. Synthesis and evaluation of the diarylthiourea analogs as novel anti-cancer agents. Bioorg. Med. Chem. Lett. 2015, 25, 1301-1305. [CrossRef] [PubMed]

34. Rauf, M.K.; Zaib, S.; Talib, A.; Ebihara, M.; Badshah, A.; Bolte, M.; Iqbal, J. Solution-phase microwave assisted parallel synthesis, biological evaluation and in silico docking studies of $N, N^{\prime}$-disubstituted thioureas derived from 3-chlorobenzoic acid. Bioorg. Med. Chem. 2016, 24, 4452-4463. [CrossRef] [PubMed]

35. Liu, C.J.; Yu, S.L.; Liu, Y.P.; Dai, X.J.; Wu, Y.; Li, R.J.; Tao, J.C. Synthesis, cytotoxic activity evaluation and HQSAR study of novel isosteviol derivatives as potential anticancer agents. Eur. J. Med. Chem. 2016, 115, 26-40. [CrossRef] [PubMed]

36. El-Hossary, E.M.; Förstner, K.U.; François, P.; Baud, D.; Streker, K.; Schrenzel, J.; Ohlsen, K.; Holzgrabe, U. A Novel Mechanism of Inactivating Antibacterial Nitro Compounds in the Human Pathogen Staphylococcus aureus by Overexpression of a NADH-Dependent Flavin Nitroreductase. Antimicrob. Agents Chemother. 2018, 62, e01510-e01517. [CrossRef] [PubMed]

37. Chu, P.S.; Lopez, M.I.; Abraham, A.; El Said, K.R.; Plakas, S.M. Residue depletion of nitrofuran drugs and their tissue-bound metabolites in channel catfish (Ictalurus punctatus) after oral dosing. J. Agric. Food Chem. 2008, 56, 8030-8034. [CrossRef] [PubMed]

38. Bielenica, A.; Drzewiecka-Antonik, A.; Rejmak, P.; Stefańska, J.; Koliński, M.; Kmiecik, S.; Lesyng, B.; Włodarczyk, M.; Pietrzyk, P.; Struga, M. Synthesis, structural and antimicrobial studies of type II topoisomerasetargeted copper(II) complexes of 1,3-disubstituted thiourea ligands. J. Inorg. Biochem. 2018, 182, 61-70. [CrossRef] [PubMed]

39. Clinical and Laboratory Standards Institute. Methods for Dilution Antimicrobial Susceptibility Tests for Bacteria That Grow Aerobically; Approved Standard M7-A9; CLSI: Wayne, PA, USA, 2012.

40. Clinical and Laboratory Standards Institute. Methods for Determining Bactericidal Activity of Antimicrobial Agents; Approved Guideline M26-A; CLSI: Wayne, PA, USA, 1999.

41. Clinical and Laboratory Standards Institute. Methods for Dilution Antimicrobial Susceptibility Tests for Bacteria That Grow Aerobically; Approved Standard M7-A7; CLSI: Wayne, PA, USA, 2006.

42. Clinical and Laboratory Standards Institute. Reference Method for Broth Dilution Antifungal Susceptibility Testing of Yeasts; Approved Standard. CLSI document M27-A3; CLSI: Wayne, PA, USA, 2008.

43. Küçükgüzel, I.; Tatar, E.; Küçükgüzel, S.G.; Rollas, S.; De Clercq, E. Synthesis of some novel thiourea derivatives obtained from 5-[(4-aminophenoxy)methyl]-4-alkyl/aryl-2,4-dihydro-3H-1,2,4-triazole-3-thiones and evaluation as antiviral/anti-HIV and anti-tuberculosis agents. Eur. J. Med. Chem. 2008, 43, 381-392. [CrossRef] [PubMed]

44. Zhang, Y.; Hwang, H.-M.; Ekunwe, S. Comparing cytotoxicity and genotoxicity in HaCaT cells caused by 6-aminochrysene and 5,6-chrysenequinone under ultraviolet A irradiation. Environ. Toxicol. Chem. 2006, 25, 1920-1925. [CrossRef] [PubMed]

45. ISO 10993-5. Part 5: Tests for In Vitro Cytotoxicity. In 2009 Biological Evaluation of Medical Devices; International Organization for Standardization: Geneva, Switzerland, 2009. 
46. Agilent Technologies, version 1.171.37.34; CrysAlisPro.: Oxfordshire, UK, 2014.

47. Sheldrick, G.M. A short history of SHELX. Acta Crystallogr. 2008, A64, 112-122. [CrossRef] [PubMed]

Sample Availability: Samples of compound 1-30 are available from the authors. (CC BY) license (http://creativecommons.org/licenses/by/4.0/). 